\title{
THE
}

\section{Numerical Simulation of Sea Surface Directional Wave Spectra under Hurricane Wind Forcing}

\author{
II-Ju Moon \\ University of Rhode Island \\ Isaac Ginis \\ University of Rhode Island, iginis@uri.edu \\ Tetsu Hara \\ University of Rhode Island, thara@uri.edu \\ Hendrik L. Tolman \\ C. W. Wright
}

See next page for additional authors

Follow this and additional works at: https://digitalcommons.uri.edu/gsofacpubs

\begin{abstract}
Citation/Publisher Attribution
Moon, I.-J., Ginis, I., Hara, T., Tolman, H. L., Wright, C. W., \& Walsh, E. J. (2003). Numerical Simulation of Sea Surface Directional Wave Spectra under Hurricane Wind Forcing. Journal of Physical Oceanography, 33, 1680-1706. doi: 10.1175/1520-0485(2003)0332.0.CO;2

Available at: http://dx.doi.org/10.1175/1520-0485(2003)033<1680:NSOSSD>2.0.C0;2
\end{abstract}

This Article is brought to you for free and open access by the Graduate School of Oceanography at DigitalCommons@URI. It has been accepted for inclusion in Graduate School of Oceanography Faculty Publications by an authorized administrator of DigitalCommons@URI. For more information, please contact digitalcommons-group@uri.edu. 


\section{Authors}

II-Ju Moon, Isaac Ginis, Tetsu Hara, Hendrik L. Tolman, C. W. Wright, and Edward J. Walsh 


\title{
Numerical Simulation of Sea Surface Directional Wave Spectra under Hurricane Wind Forcing
}

\author{
IL-Ju Moon, IsaAc Ginis, and Tetsu Hara \\ Graduate School of Oceanography, University of Rhode Island, Narragansett, Rhode Island \\ HENDRIK L. TOLMAN \\ SAIC-GSO at NOAA/NCEP Environmental Modeling Center, Camp Springs, Maryland \\ C. W. WRight AND EDWARD J. WALSH* \\ NASA Goddard Space Flight Center Wallops Flight Facility, Wallops Island, Virginia
}

(Manuscript received 15 August 2002, in final form 30 January 2003)

\begin{abstract}
Numerical simulation of sea surface directional wave spectra under hurricane wind forcing was carried out using a high-resolution wave model. The simulation was run for four days as Hurricane Bonnie (1998) approached the U.S. East Coast. The results are compared with buoy observations and NASA Scanning Radar Altimeter (SRA) data, which were obtained on 24 August 1998 in the open ocean and on 26 August when the storm was approaching the shore. The simulated significant wave height in the open ocean reached $14 \mathrm{~m}$, agreeing well with the SRA and buoy observations. It gradually decreased as the hurricane approached the shore. In the open ocean, the dominant wavelength and wave direction in all four quadrants relative to the storm center were simulated very accurately. For the landfall case, however, the simulated dominant wavelength displays noticeable overestimation because the wave model cannot properly simulate shoaling processes. Direct comparison of the model and SRA directional spectra in all four quadrants of the hurricane shows excellent agreement in general. In some cases, the model produces smoother spectra with narrower directional spreading than do the observations. The spatial characteristics of the spectra depend on the relative position from the hurricane center, the hurricane translation speed, and bathymetry. Attempts are made to provide simple explanations for the misalignment between local wind and wave directions and for the effect of hurricane translation speed on wave spectra.
\end{abstract}

\section{Introduction}

Hurricane-generated wave fields are of interest both scientifically for understanding wind-wave interaction physics and operationally for predicting potentially hazardous conditions for ship navigation and coastal regions. A hurricane with intense and fast-varying winds produces a severe and complex ocean wave field that can propagate for thousands of kilometers away from the storm center, resulting in dramatic variation of the wave field in space and time (Barber and Ursell 1948).

In recent years there have been considerable efforts made to measure the directional spectra of hurricane-

\footnotetext{
* Current affiliation: NOAA/Environmental Technology Laboratory, Boulder, Colorado.
}

Corresponding author address: Il-Ju Moon, Graduate School of Oceanography, University of Rhode Island, Narragansett, RI 02882. E-mail: mij@gso.uri.edu generated surface waves and to investigate its spectral characteristics. Wyatt (1995) described measurements of the directional spectra of storm waves using highfrequency radar to explain the effect of fetch on the directional spectrum of Celtic Sea storm waves. Holt et al. (1998) examined the capability of synthetic aperture radar imagery from $E R S-1$ satellite to track the wave fields emanating from an intense storm over a several day period. Wright et al. (2001) and Walsh et al. (2002) studied the spatial variation of hurricane directional wave spectra for both open ocean and landfall cases using the National Aeronautics and Space Administration (NASA) Scanning Radar Altimeter (SRA) for the first time. These measurements have provided detailed wave characteristics only at a specific space and time.

Ocean wave modeling is a very useful and convenient way to obtain the spatial and temporal distribution of directional spectra without the limitations associated with measurements, although the model output may differ from observations because of uncer- 


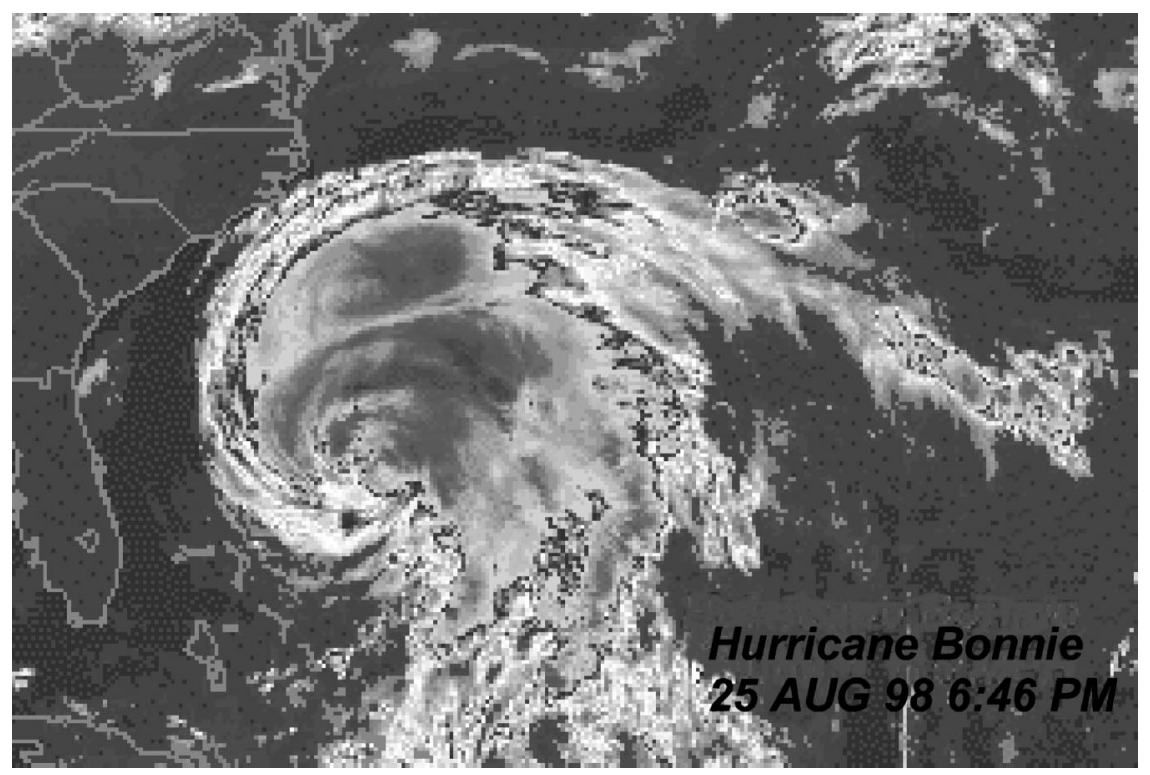

FIG. 1. Hurricane Bonnie from satellite image at 1846 UTC 25 Aug 1998.

TABLE 1. Best track of Hurricane Bonnie, central pressure, maximum wind speed, radii with wind speed of $18 \mathrm{~m} \mathrm{~s}^{-1}, 26 \mathrm{~m} \mathrm{~s}^{-1}$, and the maximum in all quadrants (NE, SE, SW, and NW) of a hurricane from the message files provided by the National Hurricane Center.

\begin{tabular}{|c|c|c|c|c|c|c|c|c|c|c|c|c|c|}
\hline \multirow{3}{*}{$\begin{array}{l}\text { Date/time } \\
\text { (UTC) }\end{array}$} & & & \multirow{3}{*}{$\begin{array}{c}\text { Central } \\
\text { pressure } \\
(\mathrm{hPa})\end{array}$} & \multirow{3}{*}{$\begin{array}{l}\text { Max wind } \\
\text { speed } \\
\text { (kt) }\end{array}$} & \multicolumn{9}{|c|}{ Radius (km) } \\
\hline & \multicolumn{2}{|c|}{ Position } & & & \multirow[b]{2}{*}{ Max } & \multicolumn{4}{|c|}{$18 \mathrm{~m} \mathrm{~s}^{-1}$} & \multicolumn{4}{|c|}{$26 \mathrm{~m} \mathrm{~s}^{-1}$} \\
\hline & lat $\left({ }^{\circ} \mathrm{N}\right)$ & lon $\left({ }^{\circ} \mathrm{W}\right)$ & & & & $\mathrm{NE}$ & SE & SW & NW & $\mathrm{NE}$ & $\mathrm{SE}$ & SW & NW \\
\hline $22 / 0000$ & 21.1 & 67.3 & 991 & 70 & 74 & 232 & 93 & 93 & 232 & 93 & 46 & 46 & 93 \\
\hline 0600 & 21.8 & 68.7 & 989 & 75 & 46 & 278 & 93 & 93 & 278 & 139 & 46 & 46 & 93 \\
\hline 1200 & 22.3 & 69.8 & 980 & 85 & 46 & 278 & 93 & 93 & 278 & 139 & 46 & 46 & 93 \\
\hline 1800 & 23.0 & 70.5 & 970 & 90 & 46 & 324 & 167 & 167 & 324 & 139 & 46 & 46 & 139 \\
\hline $23 / 0000$ & 23.4 & 71.0 & 962 & 95 & 46 & 324 & 167 & 167 & 324 & 139 & 139 & 139 & 139 \\
\hline 0600 & 23.8 & 71.3 & 960 & 100 & 46 & 278 & 278 & 185 & 278 & 139 & 139 & 139 & 139 \\
\hline 1200 & 24.1 & 71.5 & 958 & 100 & 46 & 278 & 278 & 185 & 278 & 139 & 139 & 139 & 139 \\
\hline 1800 & 24.4 & 71.7 & 955 & 100 & 46 & 324 & 278 & 185 & 278 & 185 & 167 & 139 & 139 \\
\hline $24 / 0000$ & 24.8 & 71.8 & 954 & 100 & 46 & 324 & 324 & 185 & 278 & 185 & 185 & 139 & 139 \\
\hline 0600 & 25.2 & 72.1 & 960 & 100 & 74 & 324 & 324 & 232 & 278 & 185 & 185 & 139 & 139 \\
\hline 1200 & 25.6 & 72.4 & 962 & 100 & 74 & 324 & 324 & 232 & 278 & 185 & 185 & 139 & 139 \\
\hline 1800 & 26.1 & 72.8 & 963 & 100 & 74 & 371 & 324 & 232 & 371 & 232 & 185 & 139 & 232 \\
\hline $25 / 0000$ & 26.9 & 73.2 & 963 & 100 & 74 & 371 & 324 & 232 & 371 & 232 & 185 & 139 & 232 \\
\hline 0600 & 27.8 & 73.8 & 962 & 100 & 74 & 324 & 278 & 232 & 324 & 250 & 232 & 158 & 285 \\
\hline 1200 & 28.8 & 74.7 & 963 & 100 & 74 & 278 & 278 & 232 & 306 & 250 & 232 & 158 & 185 \\
\hline 1800 & 29.8 & 75.6 & 963 & 100 & 74 & 278 & 232 & 232 & 324 & 250 & 204 & 158 & 185 \\
\hline $26 / 0000$ & 30.8 & 76.4 & 958 & 100 & 74 & 371 & 278 & 232 & 371 & 232 & 232 & 158 & 185 \\
\hline 0600 & 31.7 & 77.3 & 964 & 100 & 74 & 371 & 278 & 232 & 278 & 232 & 232 & 158 & 185 \\
\hline 1200 & 32.7 & 77.8 & 965 & 100 & 74 & 371 & 278 & 232 & 278 & 232 & 232 & 139 & 185 \\
\hline 1800 & 33.4 & 77.8 & 962 & 100 & 83 & 371 & 278 & 167 & 139 & 232 & 185 & 111 & 111 \\
\hline $27 / 0000$ & 34.0 & 77.7 & 963 & 95 & 83 & 371 & 278 & 167 & 139 & 232 & 185 & 111 & 111 \\
\hline 0600 & 34.5 & 77.5 & 965 & 85 & 83 & 278 & 324 & 185 & 139 & 232 & 232 & 139 & 111 \\
\hline 1200 & 34.9 & 77.1 & 974 & 75 & 83 & 139 & 185 & 83 & 83 & 232 & 324 & 167 & 139 \\
\hline 1800 & 35.4 & 76.6 & 980 & 60 & 83 & 167 & 417 & 278 & 111 & 93 & 139 & 74 & 74 \\
\hline $28 / 0000$ & 35.8 & 75.9 & 983 & 65 & 111 & 167 & 417 & 278 & 111 & 93 & 139 & 74 & 74 \\
\hline 0600 & 36.2 & 75.1 & 985 & 75 & 111 & 250 & 371 & 278 & 139 & 139 & 185 & 93 & 93 \\
\hline 1200 & 36.7 & 74.3 & 990 & 65 & 111 & 250 & 371 & 278 & 139 & 185 & 93 & 93 & 93 \\
\hline 1800 & 37.3 & 73.2 & 991 & 60 & 111 & 278 & 371 & 222 & 139 & 111 & 222 & 93 & 167 \\
\hline $29 / 0000$ & 38.3 & 71.4 & 993 & 45 & 111 & 139 & 389 & 222 & 139 & 111 & 222 & 139 & 167 \\
\hline
\end{tabular}




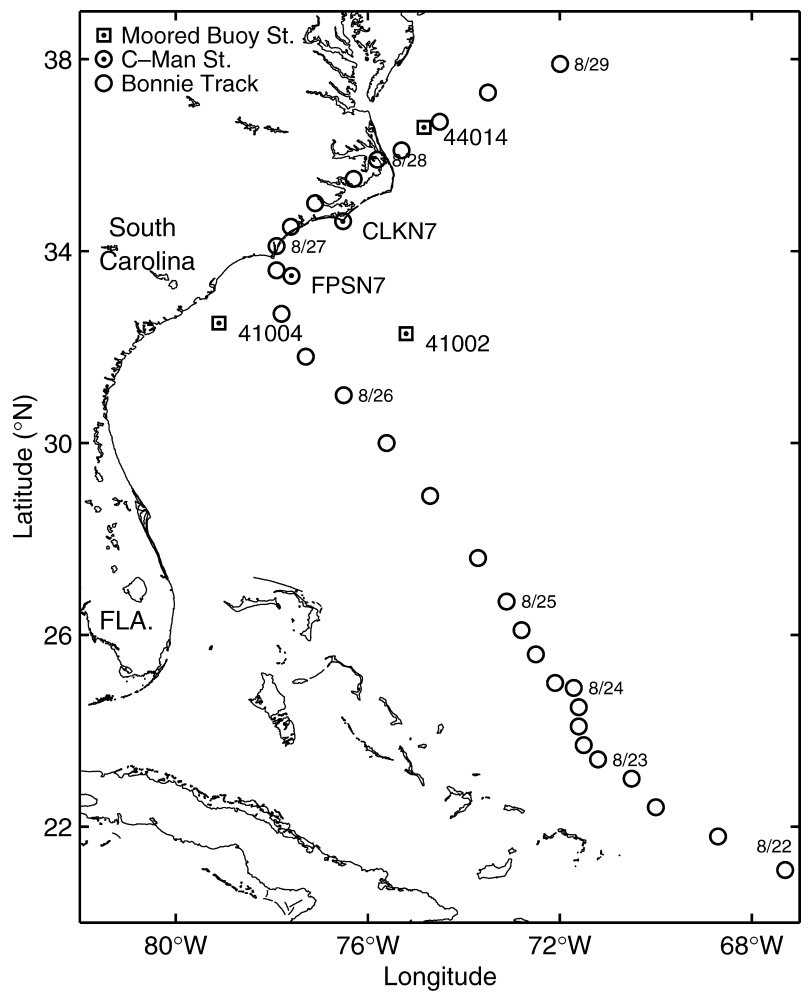

FIG. 2. Track of Hurricane Bonnie and locations of moored buoy and C-Man stations. Circles represent the position of hurricane center every $6 \mathrm{~h}$.

tainties in wind input, model physics, and numerics. Recently, considerable improvements have been made in predicting ocean wave directional spectra. Until the late 1980s, many models were developed using simple nonlinear interaction approximations and assumptions on spectral shape (first- and second-generation models). After the Sea Wave Model Project (SWAMP) study in the mid-1980s, through community efforts, the Wave Model (WAM) was developed with explicit treatment of nonlinear interactions (third-generation models), essentially replacing all previous models (WAMDI Group 1988; Komen et al. 1994). The WAM has been verified and applied to wave hindcast and forecast, air-sea coupling, and data assimilation over many seas of the world (Dell'Osso et al. 1992; Bauer et al. 1992; Monaldo and Beal 1998; Prasadkumar et al. 2000). Recently, a new ocean surface wave model, WAVEWATCH III (Tolman 1999), was developed at the National Oceanic and Atmospheric Administration-National Centers for Environmental Prediction (NOAA-NCEP) in the spirit of the WAM. It is designed with more general governing transport equations that permit full coupling with ocean models, improved propagation schemes (third order), improved physics integration scheme, and improved physics of wave growth and decay. The WAVEWATCH III (WW3) has been validated over a global-scale wave forecast and a regional wave forecast (Tolman 1998, 2002; Tolman et al. 2002; Wingeart et al. 2001).

Directional spectra associated with a hurricane are very complicated and have quickly varying characteristics in time and space due to the hurricane's movement and wind curvature. Under hurricane wind forcing, therefore, numerical modeling of sea surface directional wave spectra requires numerical grids and input wind of high resolution. A wave model with its coarse resolution tends to provide an inaccurate wave forecast, especially in predicting the direction and arrival time of swell in coastal areas. To date, there have been no studies investigating the spectral characteristics of the hurricane-generated wind waves using such a high-resolution model and comparing the results with detailed in situ spectral observations in all quadrants of a hurricane.

In the present study, we design a high-resolution wave model and evaluate the model's performance under hurricane wind forcing using various observational data. For model evaluation, we use the dataset of surface directional wave spectra obtained from NASA SRA during the passage of Hurricane Bonnie (Wright et al. 2001; Walsh et al. 2002). Along the track of Bonnie, available buoys and C-man station data of the National Data Buoy Center (NDBC) are also used. From the modeling and observations, we focus on investigating the spectral variations of hurricane-generated waves, which are dependent on location from the hurricane center and hurricane speed. This is the first detailed comparison of the spatial distribution of the hurricane generated directional wave spectra between model simulations and observations in both open ocean and landfall cases.

The dataset used in the present study including NASA SRA, NDBC buoy, station data, and Bonnie wind fields are described in section 2. A brief outline of the WAVEWATCH III is given in section 3. Section 4 describes comparisons of the simulated hurricane-generated wave spectra with the observations and explains the spectral characteristics of hurricane waves. The summary and conclusions are given in the last section.

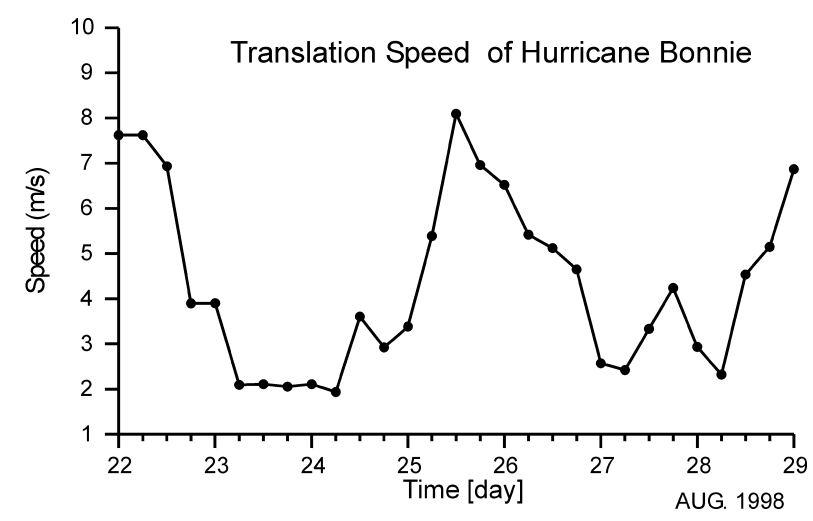

FIG. 3. Variation of Hurricane Bonnie translation speeds. 


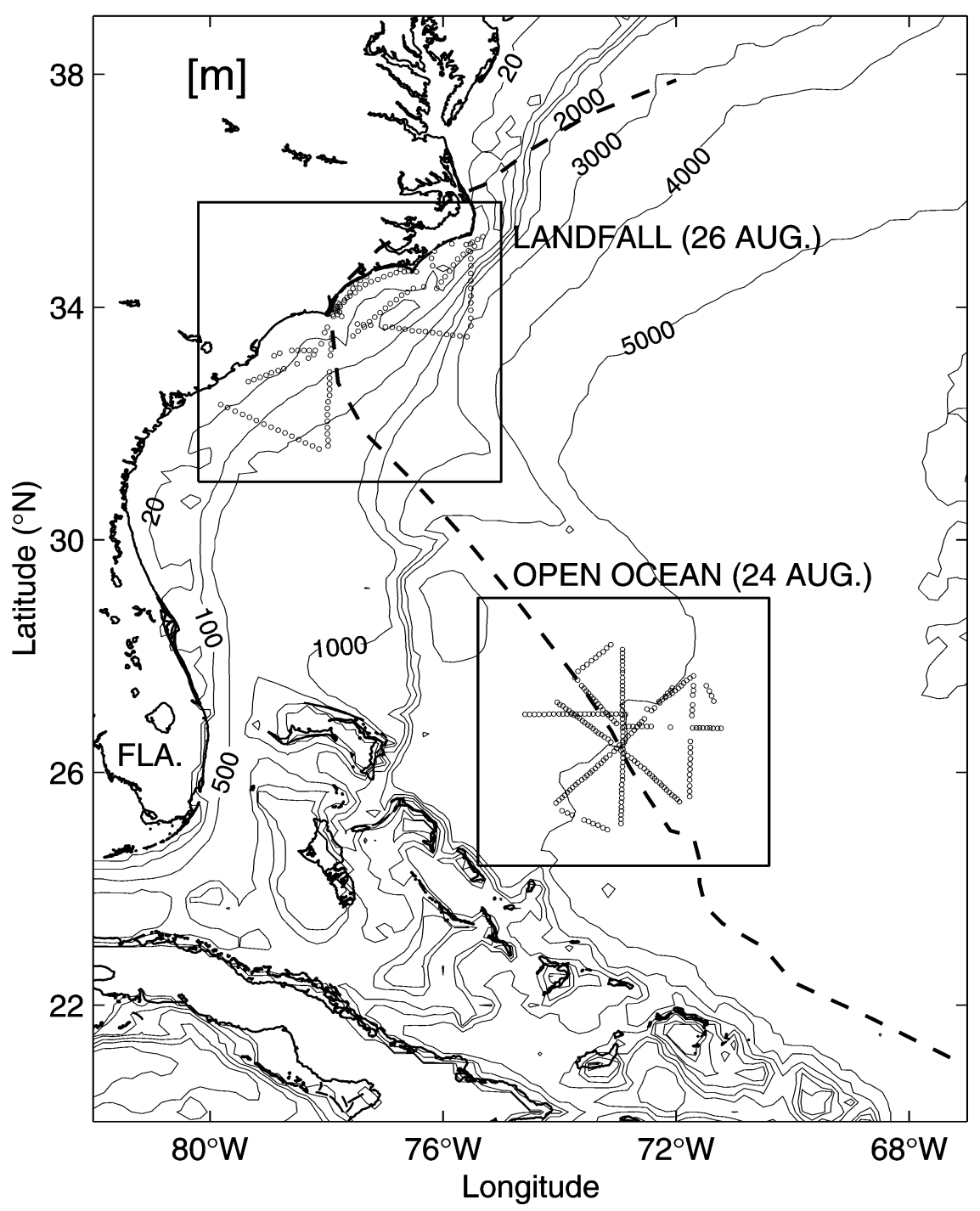

FIG. 4. Topography of the study area and observation points of SRA directional wave spectra in the open water on 24 Aug 1998 and at landfall on 26 Aug 1998. Dashed line represents the track of Bonnie.

\section{Dataset description}

\section{a. Hurricane Bonnie}

Hurricane Bonnie (Fig. 1) was one of the most powerful hurricanes to directly hit the coast of North Carolina in recent decades inflicting $\$ 360$ million in insured property damage (Avila 1998). Bonnie became a hurricane at 0600 UTC 22 August 1998 when it was located about $370 \mathrm{~km}$ north of the eastern tip of Hispaniola. Thereafter, Bonnie moved in a general west-northwest heading and reached maximum winds of $51 \mathrm{~m} \mathrm{~s}^{-1}$ and a minimum pressure of $954 \mathrm{hPa}$ about $280 \mathrm{~km}$ east of San Salvador in the Bahamas (Fig. 2 and Table 1). After a slight weakening, the eye of Bonnie passed just east of Cape Fear around 2130 UTC 26 August and then made landfall near Wilmington, as a borderline Cate- gory 2/3 hurricane on the Saffir/Simpson Scale, around 0330 UTC 27 August. The hurricane slowed down and weakened while moving over eastern North Carolina. It was then downgraded to tropical storm status. Bonnie was moving fast prior to landfall with maximum translation speed of $8.1 \mathrm{~m} \mathrm{~s}^{-1}$, while it had minimum translation speed $\left(2 \mathrm{~m} \mathrm{~s}^{-1}\right)$ when it was in the open ocean at 0600 UTC 24 August (Fig. 3). During the passage of Bonnie, wave heights up to $19 \mathrm{~m}$ were observed (Avila 1998).

\section{b. NASA Airborne Scanning Radar Altimeter data}

The observed dataset of wave spectra and wind under Hurricane Bonnie were obtained through a joint effort between the NASA Goddard Space Flight Center and 

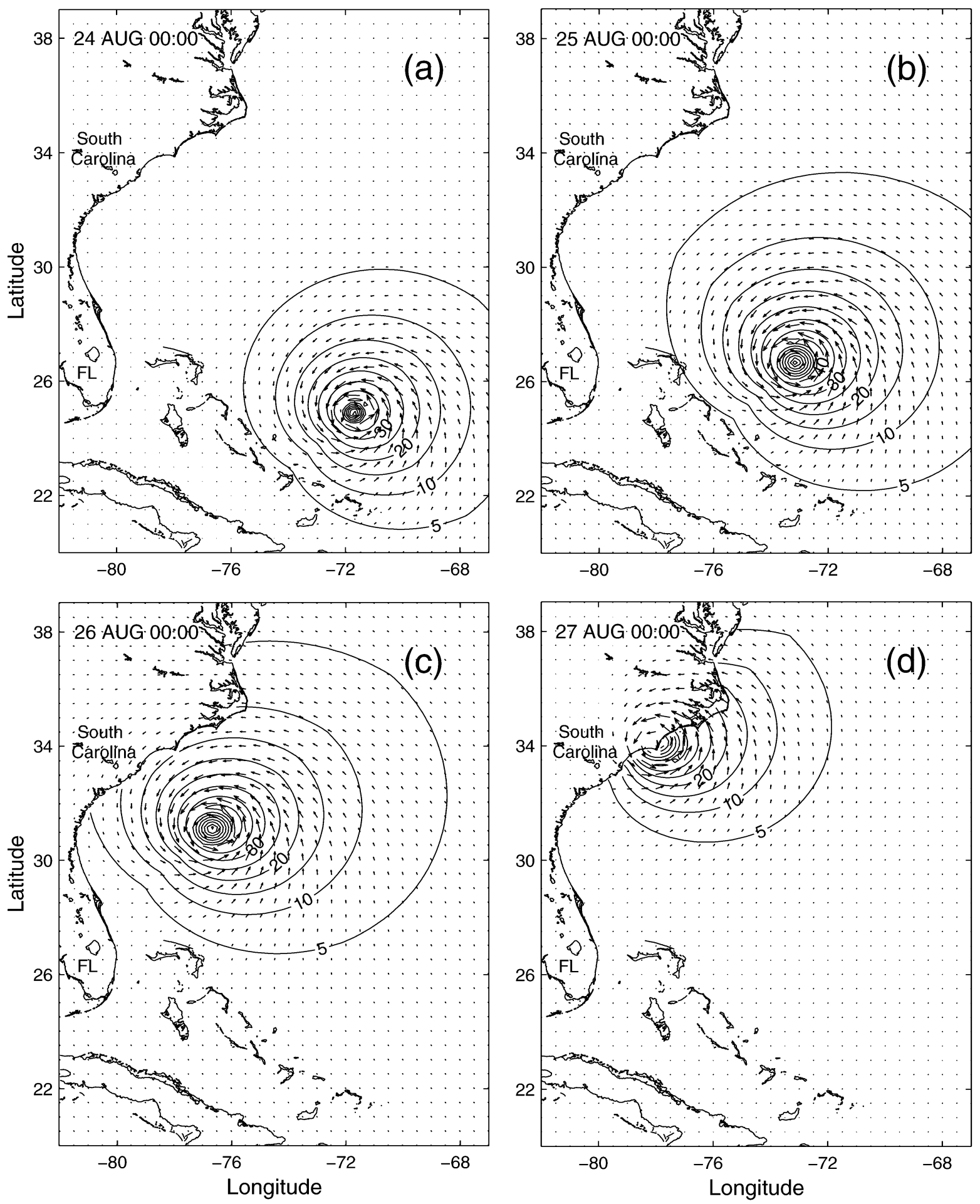

FIG. 5. Wind fields of Hurricane Bonnie obtained from the NHC message files. The maximum wind speed reaches $46 \mathrm{~m} \mathrm{~s}^{-1}$ in the open ocean and it decreases as the hurricane approaches land.

NOAA/Atlantic Oceanographic and Meteorological Laboratory/Hurricane Research Division (HRD). The NASA SRA provided the first documentation of spatial variation of the sea surface directional wave spectra throughout hurricane passage. The data were obtained on 24 August 1998 when Bonnie, a large category-3 hurricane, was $400 \mathrm{~km}$ east of Abaco Island, Bahamas, and on 26 August, when Bonnie was approaching Wil- 

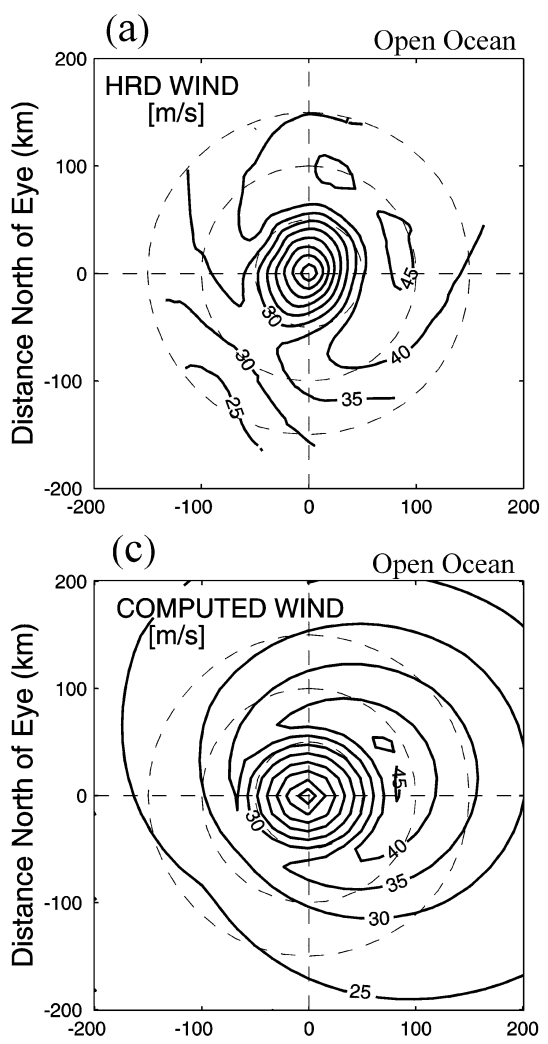

(e)

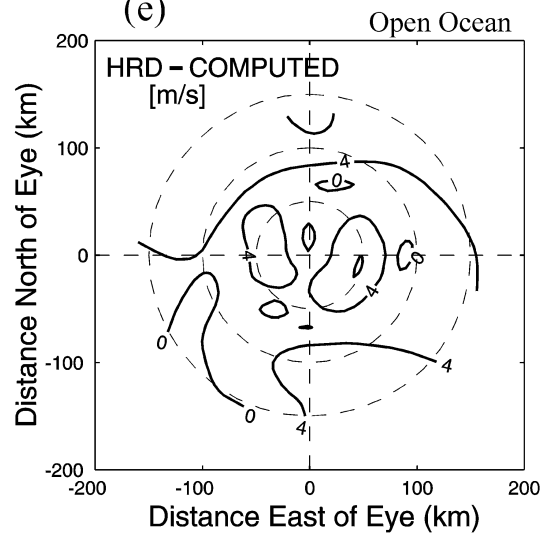

(b)

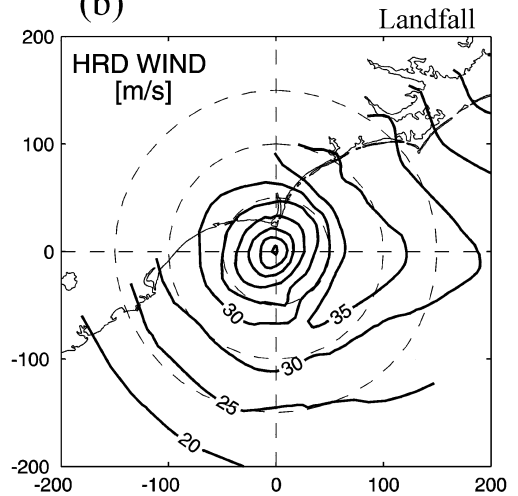

(d)
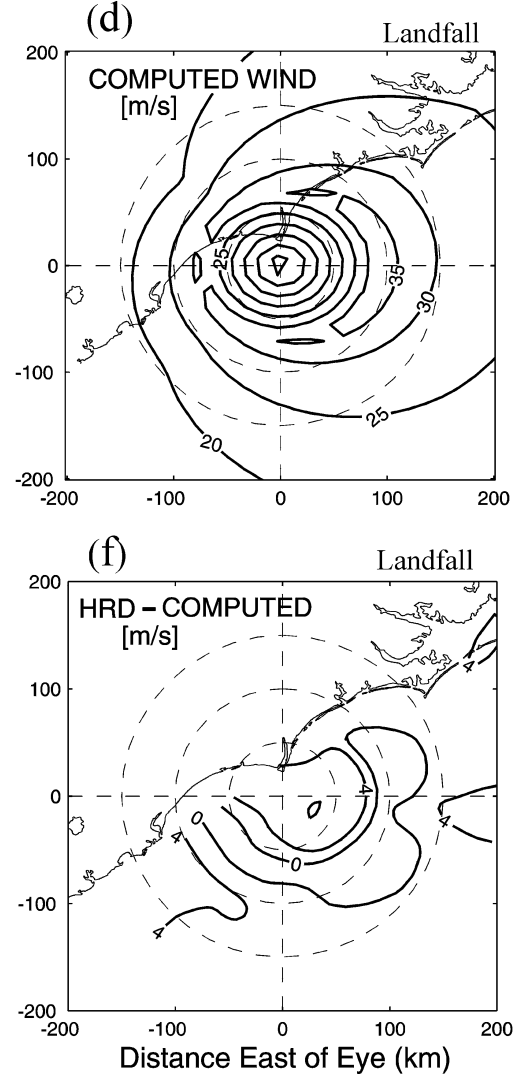

FIG. 6. Comparisons of wind speed spatial variation between HRD and model wind for the cases of (a), (c), (e) open water and (b), (d), (f) landfall.

mington, North Carolina. Figure 4 shows the topography of study areas and all SRA observation points for the open water and landfall cases.

The SRA scans a $1^{\circ}$ radar beam across the aircraft ground track to measure the elevations at 64 points on the sea surface. From the SRA scan lines, sea surface topographic maps are produced. The wave spectra were produced from the sea surface topography from 180 cross-track scan lines of the SRA. The topography was interpolated to a north- and east-oriented 256 by 256 rectangular grid of $7-\mathrm{m}$ spacing centered on the data. The elevations in the uniform grid were transformed by a two-dimensional fast Fourier transform (FFT) with wavenumber spectral resolutions of $0.0035 \mathrm{rad} \mathrm{m}^{-1}$. Whenever instantaneous elevation data are transformed, there is a directional ambiguity of $180^{\circ}$ in each of the spectral components present. The FFT puts one-half of the spectral energy in the real lobe and the other half in an artifact lobe propagating in the opposite direction. The SRA processing doubles the spectral energy of the real lobes, deletes the artifact lobes, and Doppler corrects the real lobes to compensate for the movement of the waves relative to the aircraft motion. To obtain the 
(a)
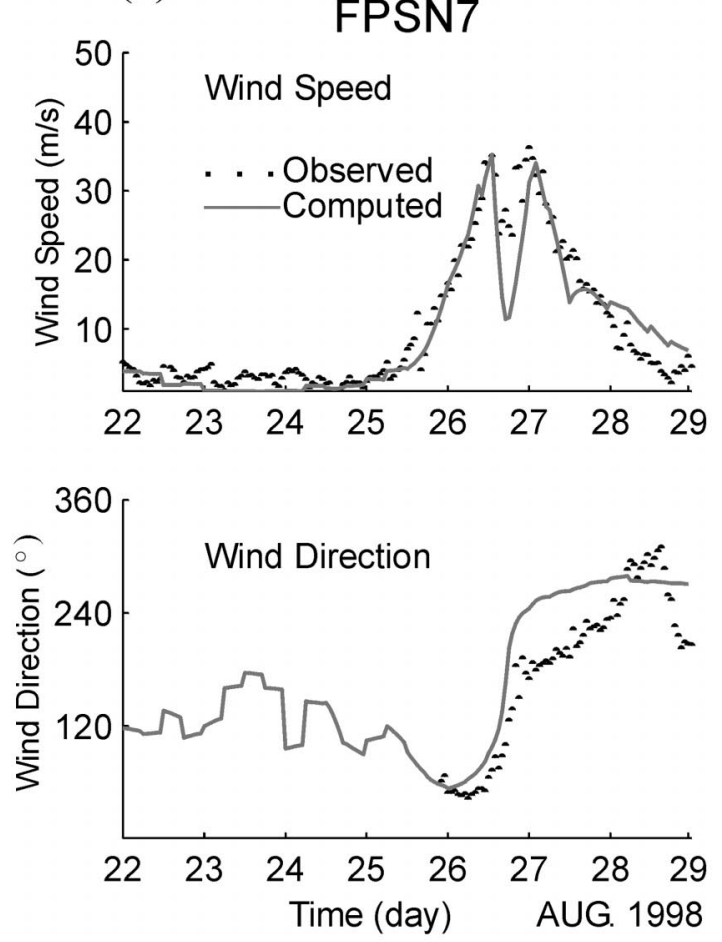

(c)

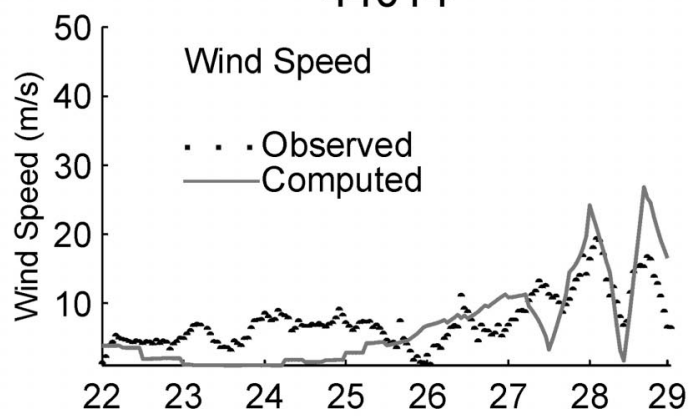

(b)
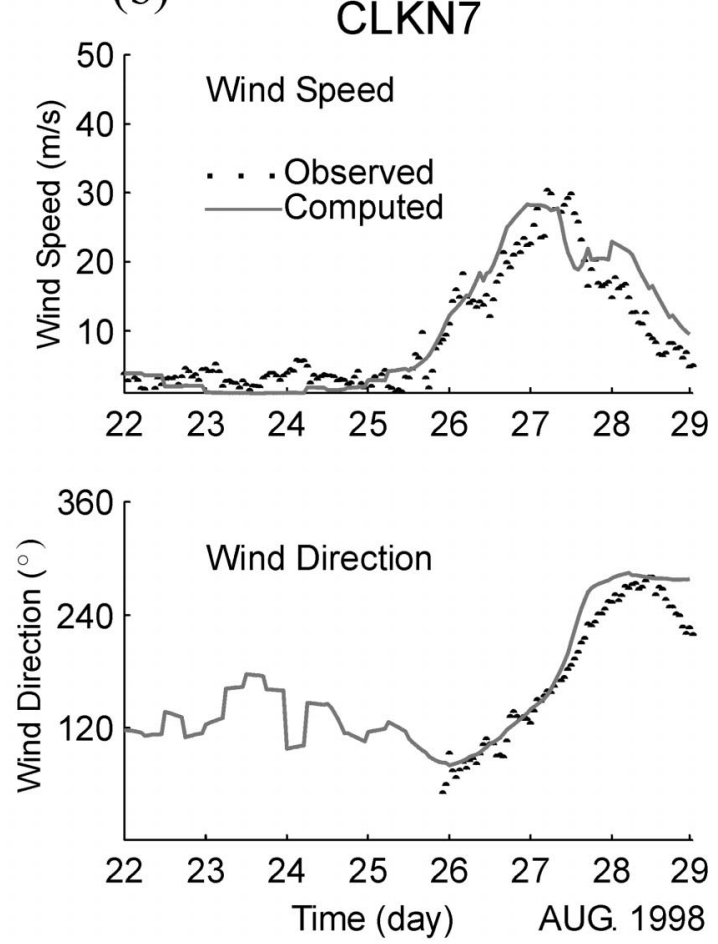

FIG. 7. Comparisons of wind speed and direction between model and buoy at (a) FPSN7, (b) CLKN7, and (c) 44014 stations.

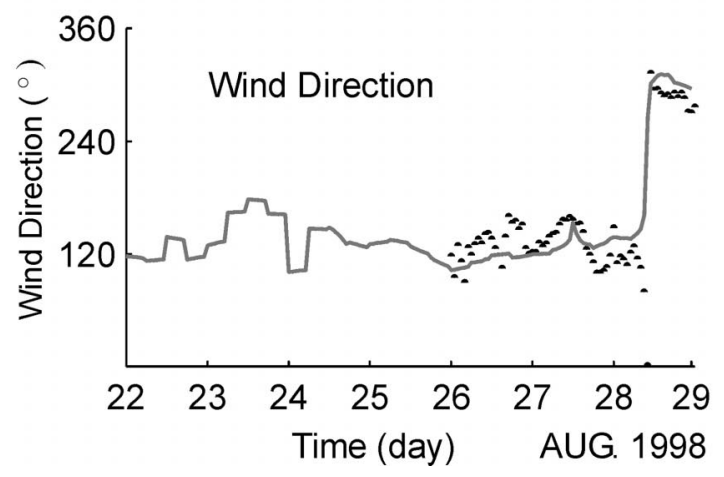


(a)

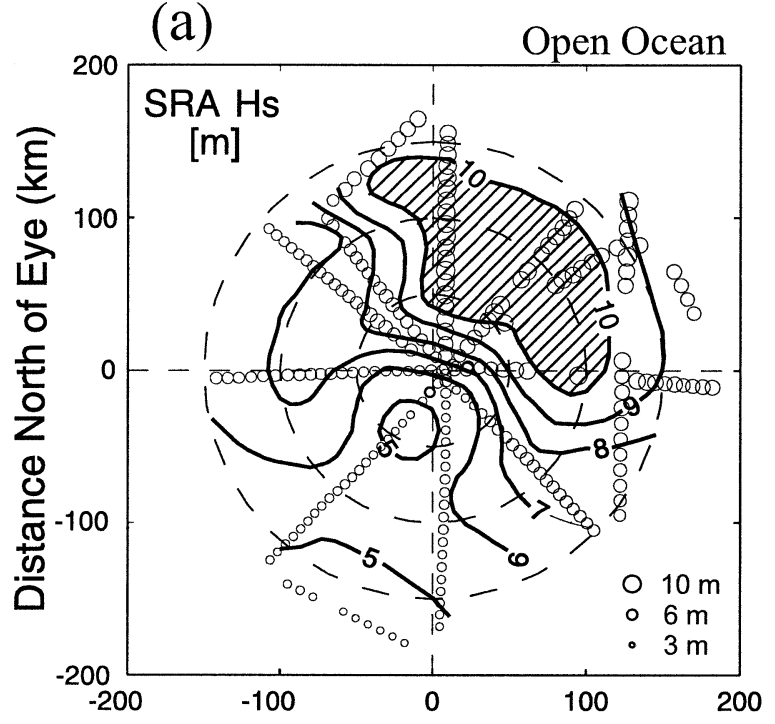

(c)

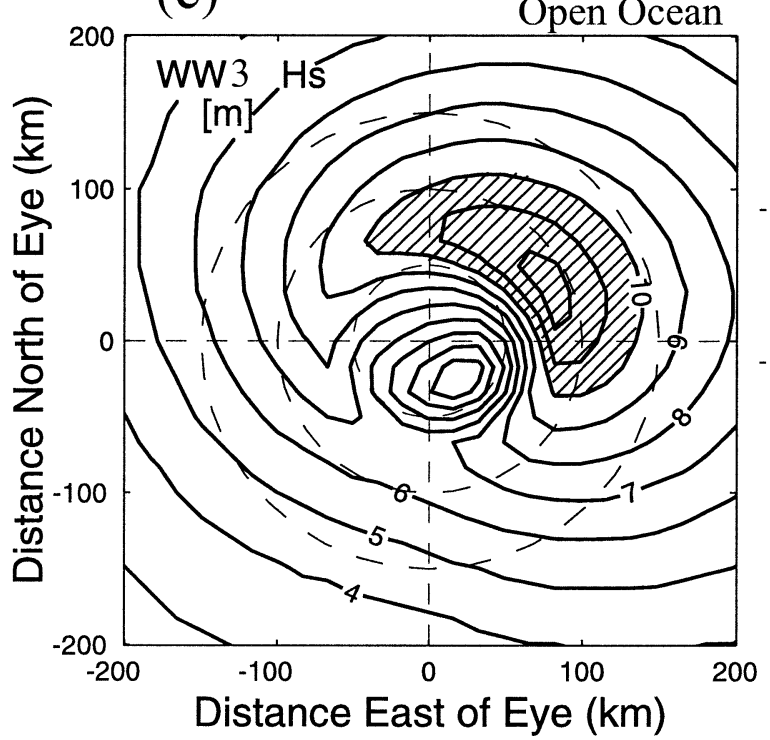

(b)

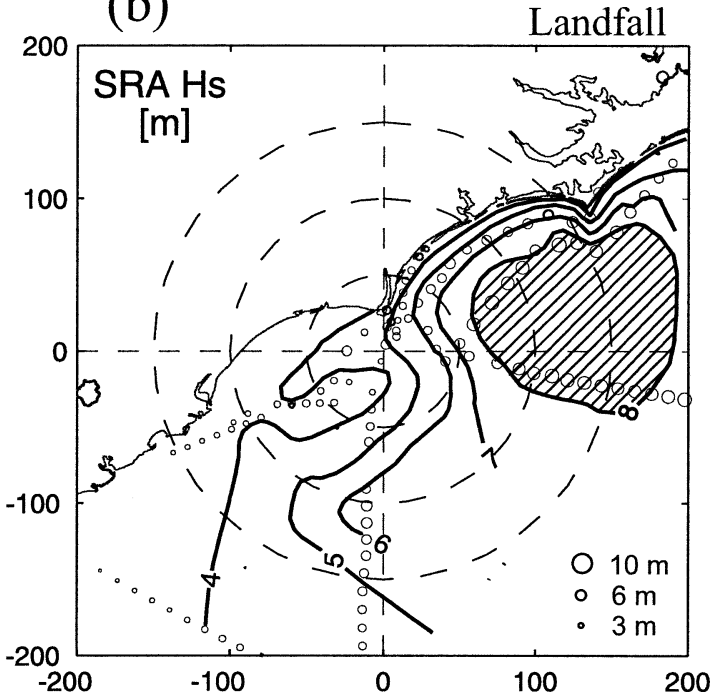

(d)

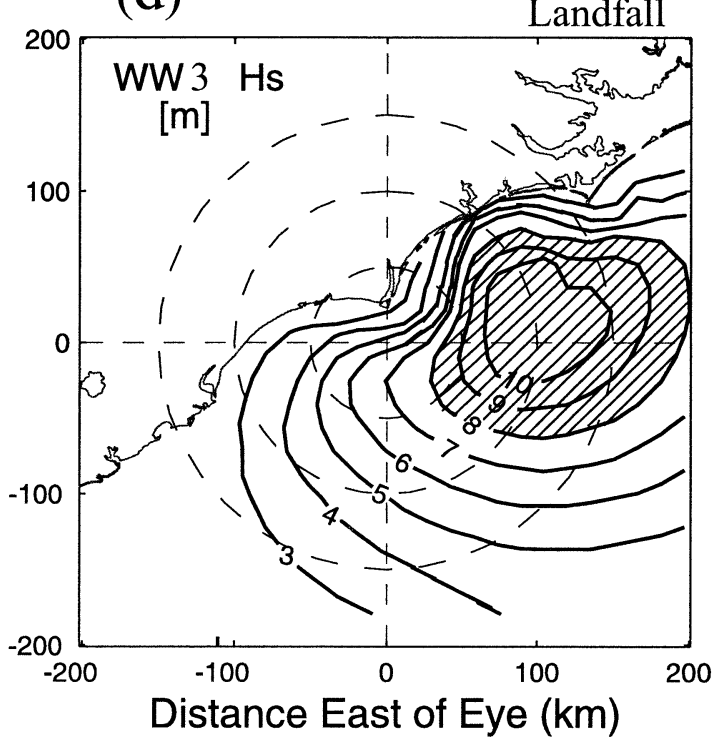

FIG. 8. Comparisons of significant wave height spatial variation between (a), (b) SRA and (c), (d) WAVEWATCH III for the case of (a), (c) open water and (b), (d) landfall. Small circles represent the SRA significant wave heights at measurement points. The radius of the circles is proportional to the significant wave height. Dashed circles (inner to outer) represent distances of 50, 100, and $150 \mathrm{~km}$ from hurricane center.

final spectra, five adjacent individual spectra were averaged and then smoothed with a 3 by 3 uniform weighting filter spanning $0.01 \mathrm{rad} \mathrm{m}^{-1}$ in wavenumber space. This procedure yielded about 90 degrees of freedom. The details of data processing are described by Walsh et al. (1985, 2002) and Wright et al. (2001).

\section{c. NDBC buoy and C-Man station data}

In order to compare model results with observations, we used time series data of wind direction, wind speed, and wave height at three moored buoys and two C-Man stations of NDBC near Bonnie's track (Fig. 2). Buoys 41002 and 41004 are 6-m Navy Oceanographic and Meteorological Automatic Device (NOMAD) buoys and buoy 44014 is a $3-\mathrm{m}$ discus buoy. The buoy data included significant wave height, wind speed and direction, and barometric pressure. All wave data were averaged over 20-min periods. The accuracy of significant wave height was $\pm 0.2 \mathrm{~m}$. Wind data from two C-Man stations, FPSN7 and CLKN7, were obtained at 44-m and 10-m height, respectively, and were adjusted to a height of $10 \mathrm{~m}$ using a logarithmic profile (Shearman and Zelenko 1989). 


\section{d. Wind fields}

Spatial distribution of the surface winds in Hurricane Bonnie used as input data to the wave model, is calculated from so-called hurricane message files provided by the National Hurricane Center (NHC) every six hours. The message files include the maximum wind speed and its radius, the radii with wind speeds of 18 and $26 \mathrm{~m} \mathrm{~s}^{-1}$ in all four quadrants of the hurricane as well as the central pressure and location of the hurricane center (Table 1). The wind field is generated using the same method as in the Geophysical Fluid Dynamics Laboratory/University of Rhode Island (GFDL/URI) coupled hurricane-ocean model (Bender and Ginis 2000) presently operational at the National Weather Service. All storm parameters in the message files are first interpolated in time to the model time step (30 min). Radial wind profiles are then calculated along northeast (NE), southeast (SE), northwest (NW), and southwest (SW) directions, correspondingly, using the following formula:

$$
\begin{aligned}
V(r) & =V_{\text {max }} \exp \left\{\frac{R_{\max }-r}{\left.\left[\frac{R_{\max }-\left(R_{18}+R_{26}\right) / 2}{\log \left(22 / V_{\max }\right)}\right]\right\}, \quad r \geq R_{\max }}\right. \\
& =\frac{r V_{\text {max }}}{R_{\max }}, \quad r<R_{\max },
\end{aligned}
$$

where $R_{18}, R_{26}$, and $R_{\max }$ are the radius with wind speed of $18 \mathrm{~m} \mathrm{~s}^{-1}, 26 \mathrm{~m} \mathrm{~s}^{-1}$, and maximum $\left(V_{\max }\right)$, respectively, given in Table 1. The two-dimensional wind field is generated by spatial interpolation of the above radial profiles azimuthally. Figure 5 shows the wind fields on 24, 25, 26, and 27 August obtained by this method. The maximum wind speed reaches $46 \mathrm{~m} \mathrm{~s}^{-1}$ in the open ocean, decreasing as Hurricane Bonnie approaches land.

During the passage of Bonnie, the NOAA HRD produced surface wind fields based on all available observations by the methods described by Powell et al. (1996). Figure 6 compares the HRD surface wind fields with the computed wind fields on 24 August 1998 in the open ocean and on 26 August 1998 at landfall, respectively. The wind speed difference (HRD - Model) is given in Fig. 6c. Generally, the wind speed distributions produced from the present method are in good agreement with those of HRD for both open ocean and landfall cases. Time series data from buoys and C-Man stations near Hurricane Bonnie's track are also used for wind comparison. Figure 7 compares speed and direction between the computed and observed wind at FPSN7, CLKN7, and 44014 stations. At 1800 UTC 26 August, the center of Hurricane Bonnie passed near the FPSN7 station (Fig. 2). At that time, the maximum wind speed of $38 \mathrm{~m} \mathrm{~s}^{-1}$ was recorded at the FPSN7 station (Fig. 7a). The computed and observed winds are in good agreement at all stations. The root mean square (rms) errors between computed and observed winds for all stations are $4.5 \mathrm{~m} \mathrm{~s}^{-1}$ in speed and $32^{\circ}$ in direction.
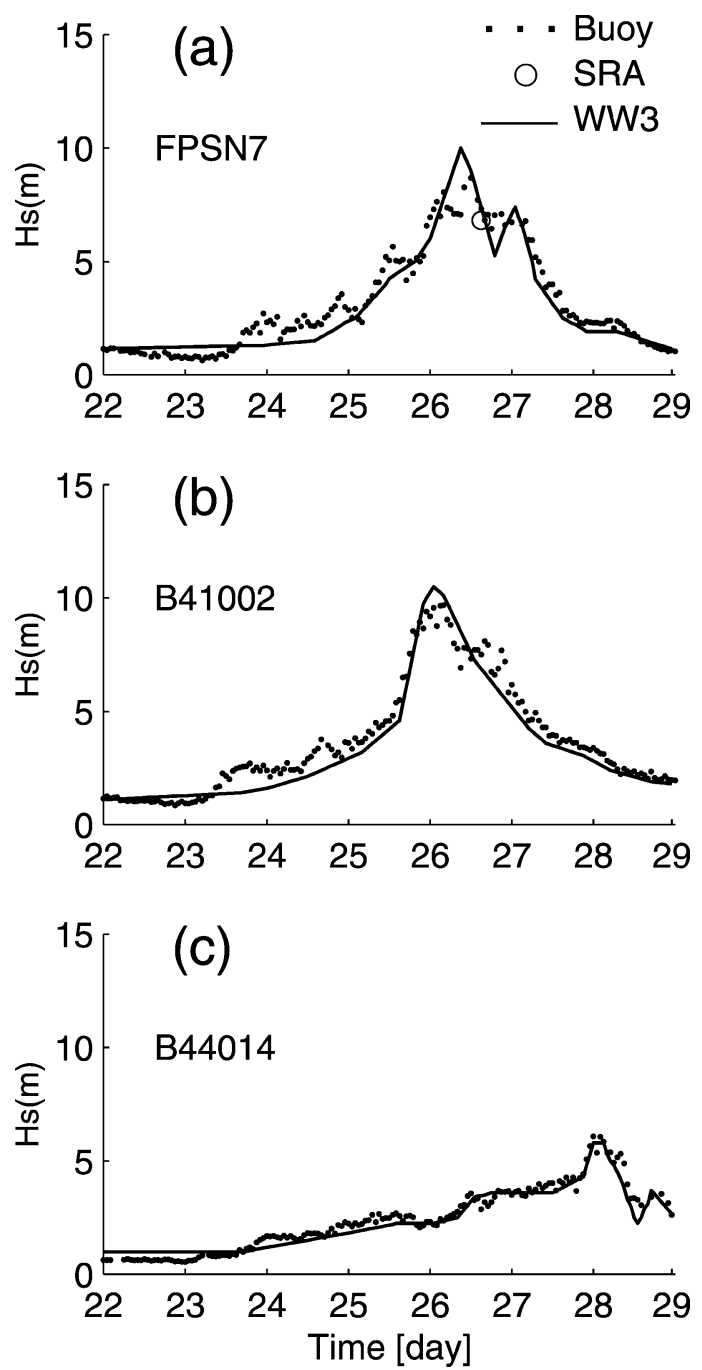

FIG. 9. Comparison of significant wave heights between WAVEWATCH III and buoy at (a) FPSN7, (b) 41002, and (c) 44014 stations.

\section{The wave model}

The WAVEWATCH III (WW3) is an ocean surface wave model developed at NOAA/NCEP in the spirit of the WAM model. It is a further development of the WAVEWATCH I developed at Delft University of Technology (Tolman 1989, 1991) and the WAVEWATCH II developed at NASA Goddard Space Flight Center (Tolman 1992). The WW3 has been used in many research programs to study surface wave dynamics, and as the operational wave model of NCEP for global and regional wave forecast (Tolman 2002; Tolman et al. 2002).

The WW3 explicitly accounts for wind input, wavewave interaction, and dissipation due to whitecapping and wave-bottom interaction. It solves the spectral action density balance equation for directional wavenumber spectra. The implicit assumption of these equations is that the medium (depth and current) as well as the wave field varies on time- and space scales that are much 

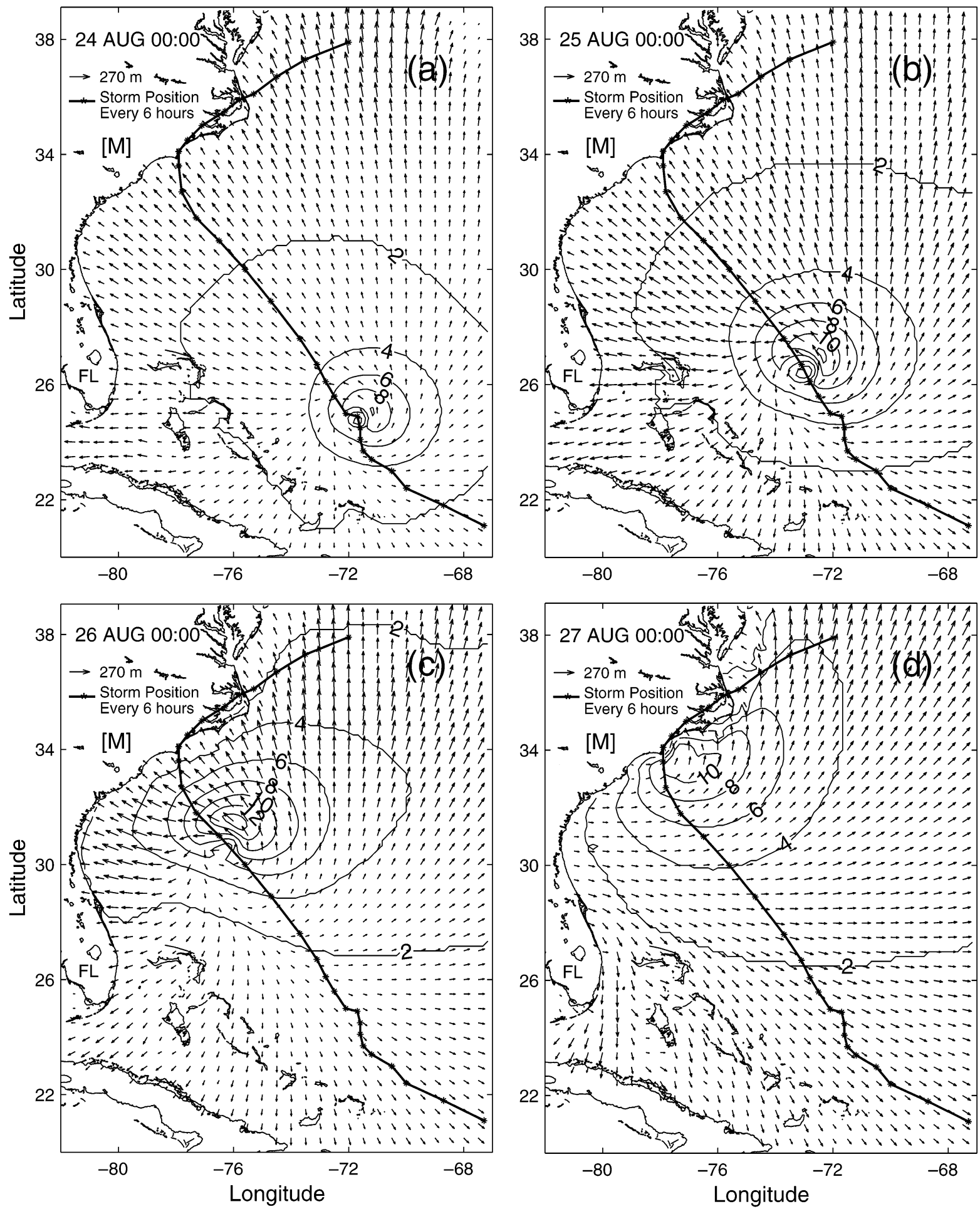

FIG. 10. Distributions of significant wave height (contours), dominant wave direction (arrows), and dominant wavelength (arrows) for Hurricane Bonnie obtained by the wave model on (a) 24, (b) 25, (c) 26, and (d) 27 Aug 1998. The arrow length is proportional to the dominant wavelength. Solid line with asterisk is the track of Bonnie every $6 \mathrm{~h}$. 

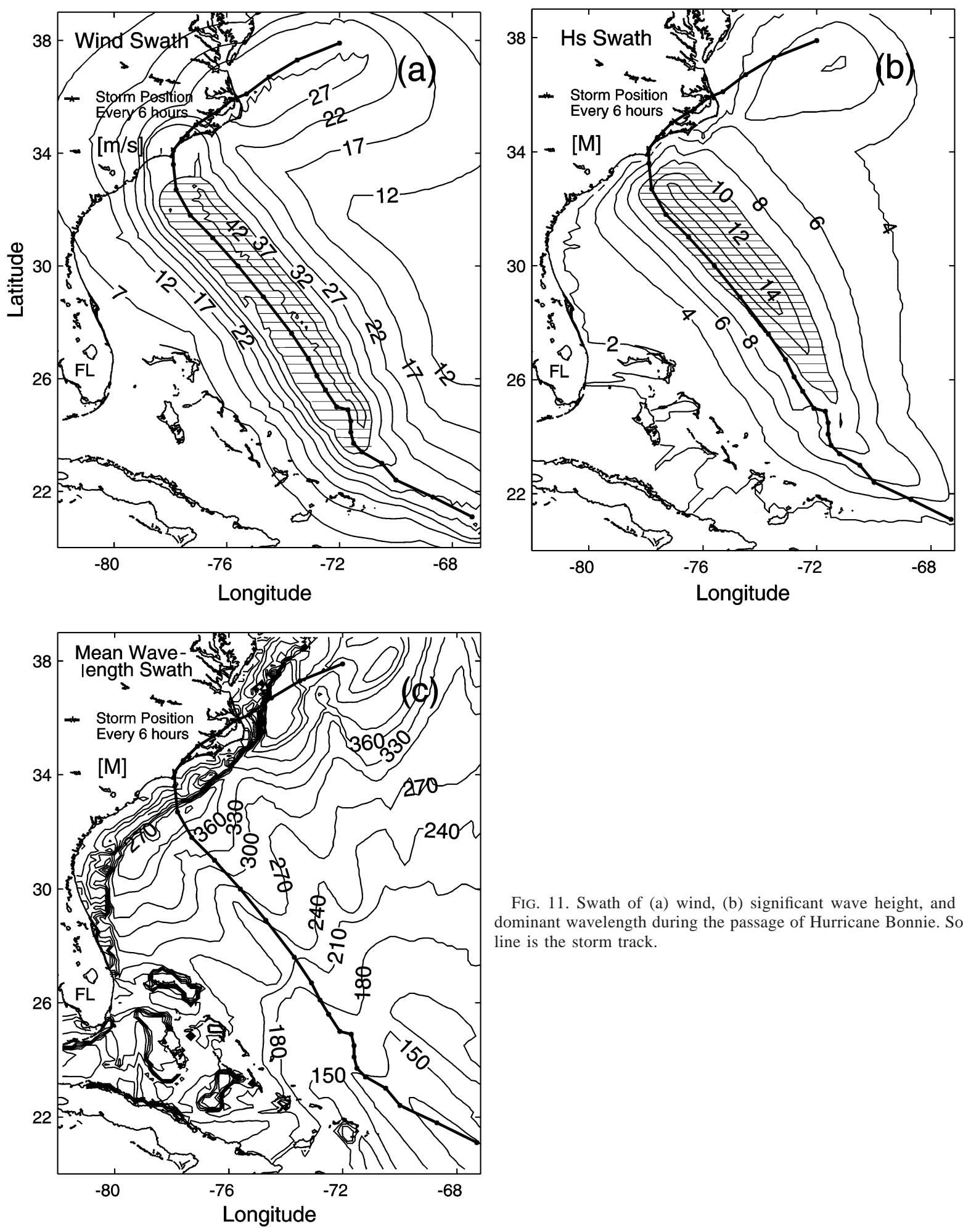

FIG. 11. Swath of (a) wind, (b) significant wave height, and (c) dominant wavelength during the passage of Hurricane Bonnie. Solid line is the storm track.

FIG. 12. Dominant waves of Hurricane Bonnie for (a) open ocean and (b) landfall cases. The circles indicate the data locations, and the radials extend in the wave propagation direction with their length proportional to the wavelength. The width of the radials is proportional to the significant wave height, so that the aspect ratio is an indication of wave steepness. The arrow indicates the HRD wind vector. 

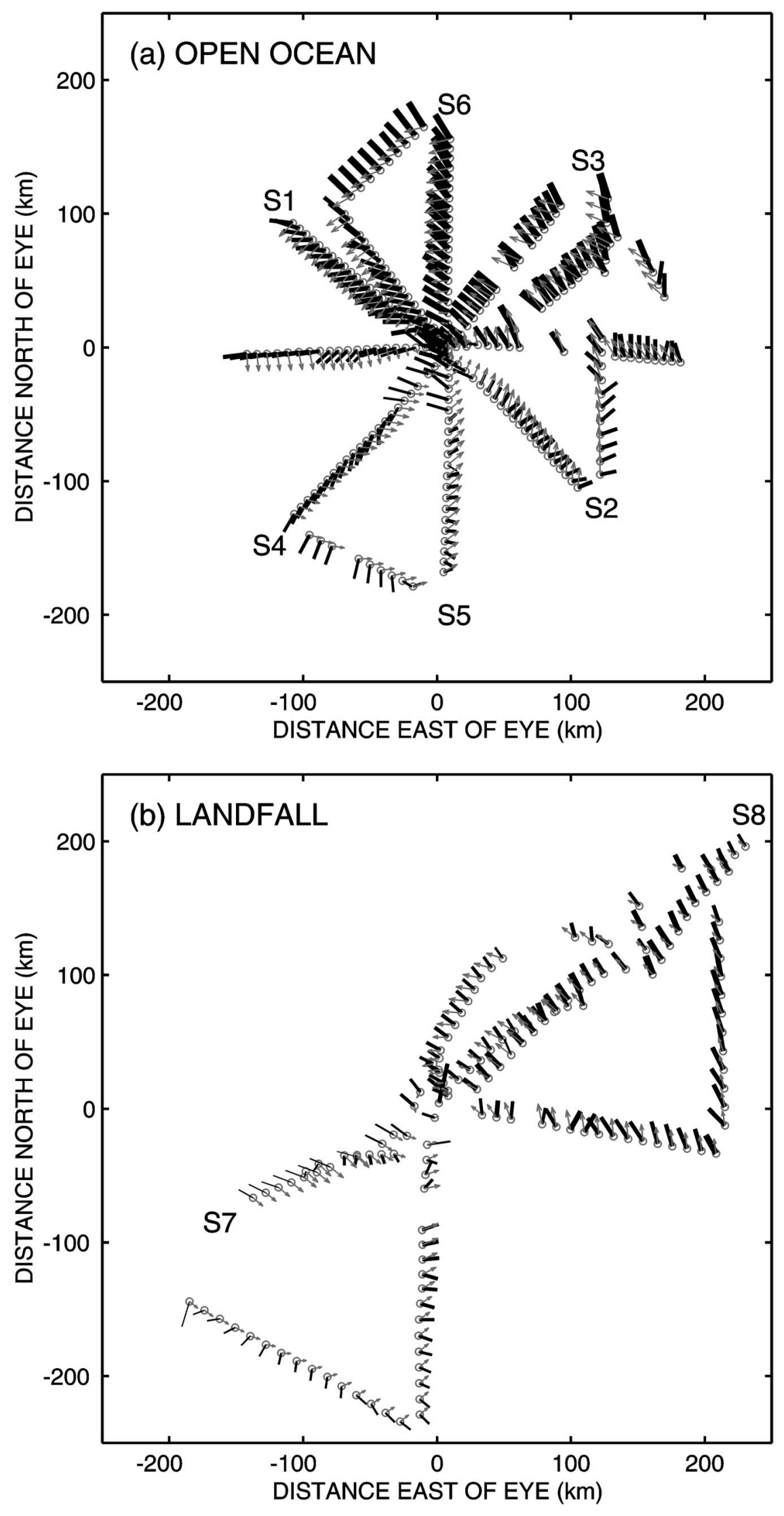


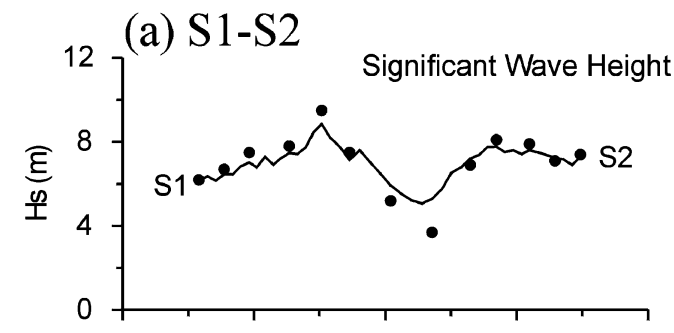

(b) S3-S4
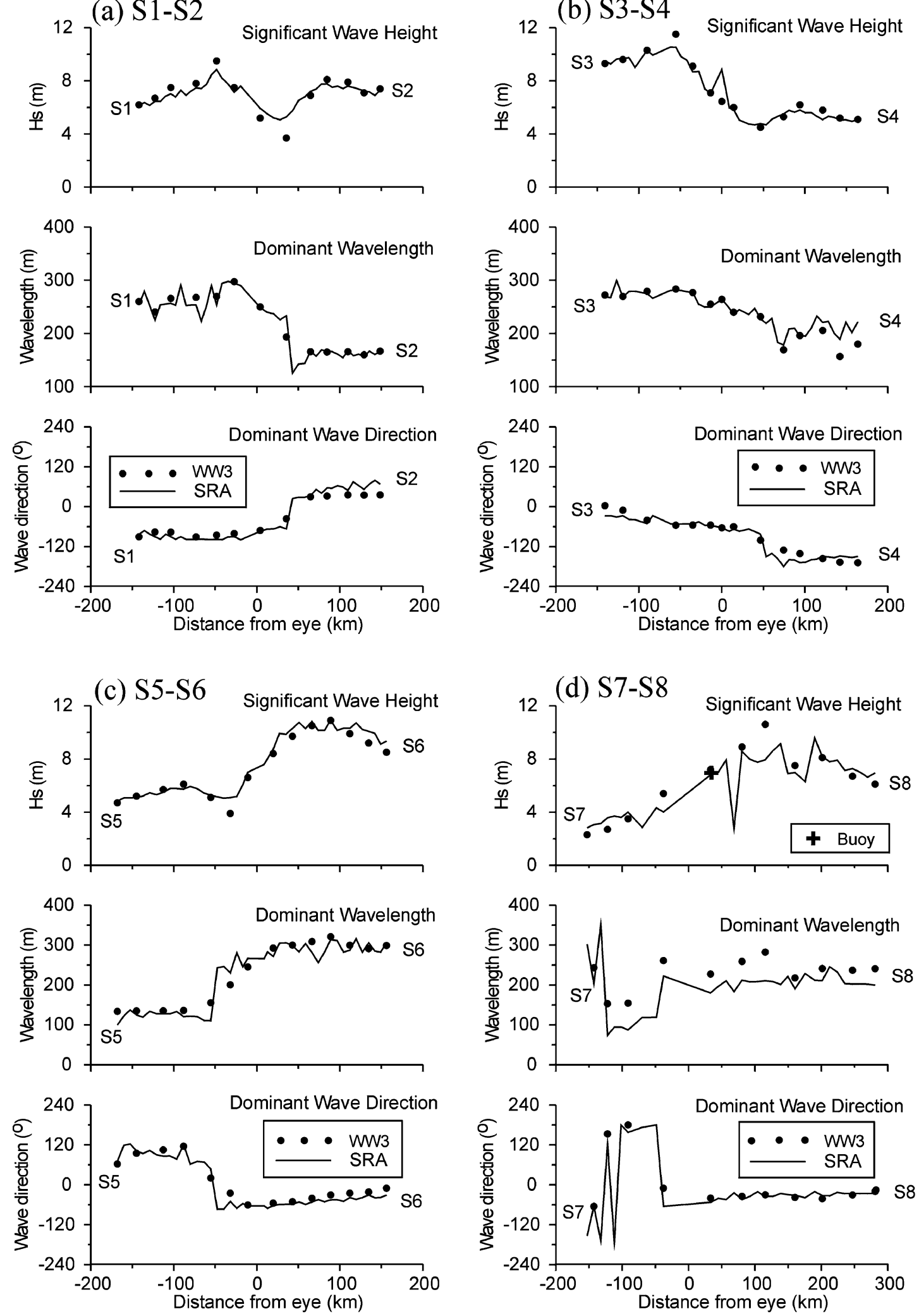

FIG. 13. Comparison of SRA observation and model simulation for significant wave height, peak wavelength, and peak wave direction along the sections across a hurricane shown in Fig. 12: (a) S1-S2, (b) S3-S4, (c) S5-S6, and (d) S7-S8. 
TABLE 2. Mean and rms errors of significant wave height, dominant wavelength, and wave direction for open ocean and landfall cases.

\begin{tabular}{|c|c|c|c|c|c|c|}
\hline \multirow[b]{2}{*}{ Wave } & \multicolumn{2}{|c|}{ Open ocean } & \multicolumn{2}{|c|}{ Landfall } & \multicolumn{2}{|c|}{ Total } \\
\hline & Mean error* & Rms error** & Mean error & Rms error & Mean error & Rms error \\
\hline Height (m) & 0.06 & 0.51 & 0.24 & 1.32 & 0.10 & 0.78 \\
\hline Length (m) & -1.45 & 17.46 & -45.28 & 50.02 & -11.56 & 28.49 \\
\hline Direction $\left({ }^{\circ}\right)$ & -3.73 & 17.69 & -10.48 & 20.05 & -5.29 & 18.26 \\
\hline
\end{tabular}

$*$ Mean error $=\frac{1}{N} \sum\left(X_{\text {obs }}-X_{\text {sim }}\right)$

** Rms error $=\sqrt{\frac{1}{N} \sum\left(X_{\mathrm{obs}}-X_{\mathrm{sim}}\right)^{2}}$

larger than the corresponding scales of a single wave. The physics included in the model do not cover conditions where waves are severely depth limited. This implies that the model can generally be applied on spatial scales (grid increments) larger than $1-10 \mathrm{~km}$ and outside the surf zone. The source terms of the WW3 use wind-wave interaction according to Chalikov and Belevich (1993), as modified by Tolman and Chalikov (1996) and Tolman (1999), discrete interaction approximation (DIA) for nonlinear interactions (as in WAM), dissipation from Tolman and Chalikov (1996), and bottom friction as in the Joint North Sea Wave Project (JONSWAP, as in most WAM models). A detailed description of the model is given by Tolman (1999).

The wave model used in this study is a high-resolution version of the WW3. Two recent studies (Tolman et al. 2002; Wingeart et al. 2001) use time step of 3600 s, wind input interval of $3600 \mathrm{~s}, 24$ spectral directions, and spatial grid of $1^{\circ} \times 1.25^{\circ}$ (global model) and $14^{\circ} \times$ $14^{\circ}$ (regional model). The present model uses $1800 \mathrm{~s}$ (time step and wind input interval), 36 directions (spectral resolution), $1 / 12 \times 1 / 12{ }^{\circ}$ (spatial grid resolution). This high-resolution model is necessary to resolve the quickly varying wave field associated with a hurricane. The grid is regularly spaced by longitude-latitude grid, extending from $20^{\circ}$ to $39^{\circ} \mathrm{N}, 67^{\circ}$ to $82^{\circ} \mathrm{W}$ and the wave spectrum is discretized using 25 frequencies extending from 0.0418 to $0.3058 \mathrm{~Hz}$ (wavelength of 16-893 m) with a logarithmic increment $f_{n+1}=1.1 f_{n}$, where $f_{n}$ is the $n$th frequency.

The model is compiled for a distributed memory environment using the Message Passing Interface (MPI) and provides output of directional wave spectra, as well as mean wave parameters such as significant wave heights $(4 \sqrt{E})$, mean wavelength $\left(2 \pi \overline{k^{-1}}\right)$, mean wave period $\left(2 \pi \overline{\sigma^{-1}}\right)$, mean wave direction, peak frequency, and peak direction. Here, $E$ is spectrum energy, $k$ is wavenumber, $\sigma$ is radian frequency. The peak (dominant) frequency is calculated from the one-dimensional frequency spectrum using a parabolic fit around the discrete peak. The peak (dominant) wavenumber (wavelength) is calculated from the peak frequency using the dispersion relation.

\section{Results and discussion}

\section{a. Significant wave heights}

Accurate prediction of hurricane-generated significant wave heights is one of the most important factors in monitoring potentially hazardous conditions for shipping routes and coastal environments. Figure 8 compares significant wave heights between the SRA observation and the model in the open ocean and at landfall. The contours of Figs. 8a and 8b estimated from the SRA observations are plotted in positions that are shifted spatially from the observation positions according to the relative vector between the eye location at the reference time and the observation time (Walsh et al. 2002). Nonuniformly spaced SRA data are interpolated to uniform grid using cubic interpolation method and smoothed to draw clear contours. The pictures are consistent with original ones (Fig. 3) indicated by Walsh et al. (2002). In the open ocean, the shaded areas (inside the $10-\mathrm{m}$ contour) of the model and the observation are very similar in their position and shape (Figs. 8a,c). For the landfall case, the shaded areas (inside the 8-m contour) are also in reasonable agreement between the two results (Figs. 8b,d). The maximum wave heights from the model are 14 and $11 \mathrm{~m}$ in the open ocean and at landfall, respectively, while those from SRA are 11 and $8.5 \mathrm{~m}$. These smaller maximum wave heights of SRA, however, may be underestimated in reality because there were not many data inside the contour. As the hurricane crossed the continental shelf and approaches the shore, the simulated significant wave heights seemed to decrease by $20 \%$, which was due to shoaling effects.

Figure 9 shows a comparison of significant wave heights $\left(H_{s}\right)$ between the model and observations at FPSN7, 41002, and 44014 stations. The maximum wave heights at the three stations reach 9,10 , and $8 \mathrm{~m}$ (in observations) and 10, 10.5, and $7 \mathrm{~m}$ (in the model), respectively. The simulated wave heights are generally in good agreement with the observations throughout Hurricane Bonnie's passage. The estimated rms errors at these stations between computed and observed wave heights are $1.4,1.3$, and $0.7 \mathrm{~m}$, respectively. Figure 10 shows distributions of significant wave height (con- 
(a)

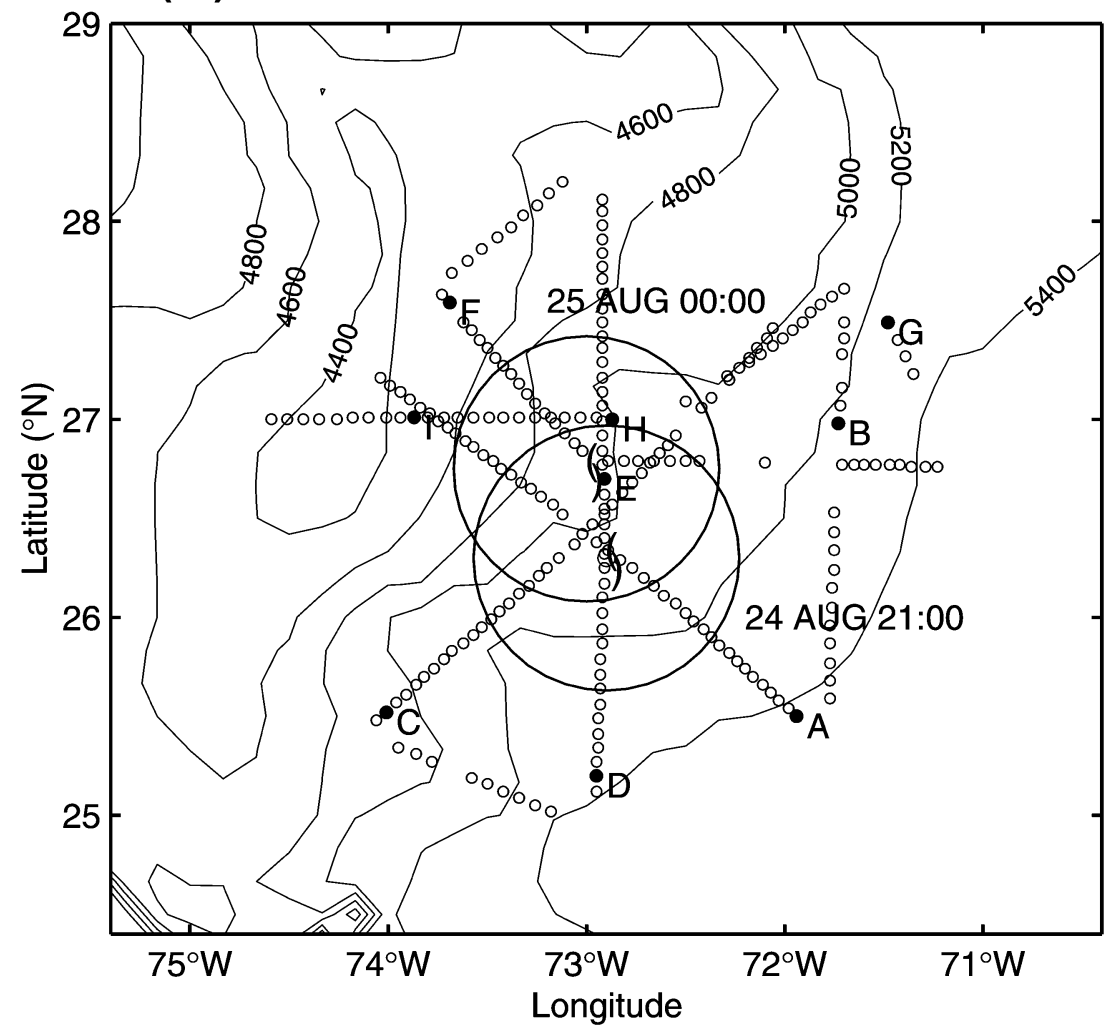

(b)

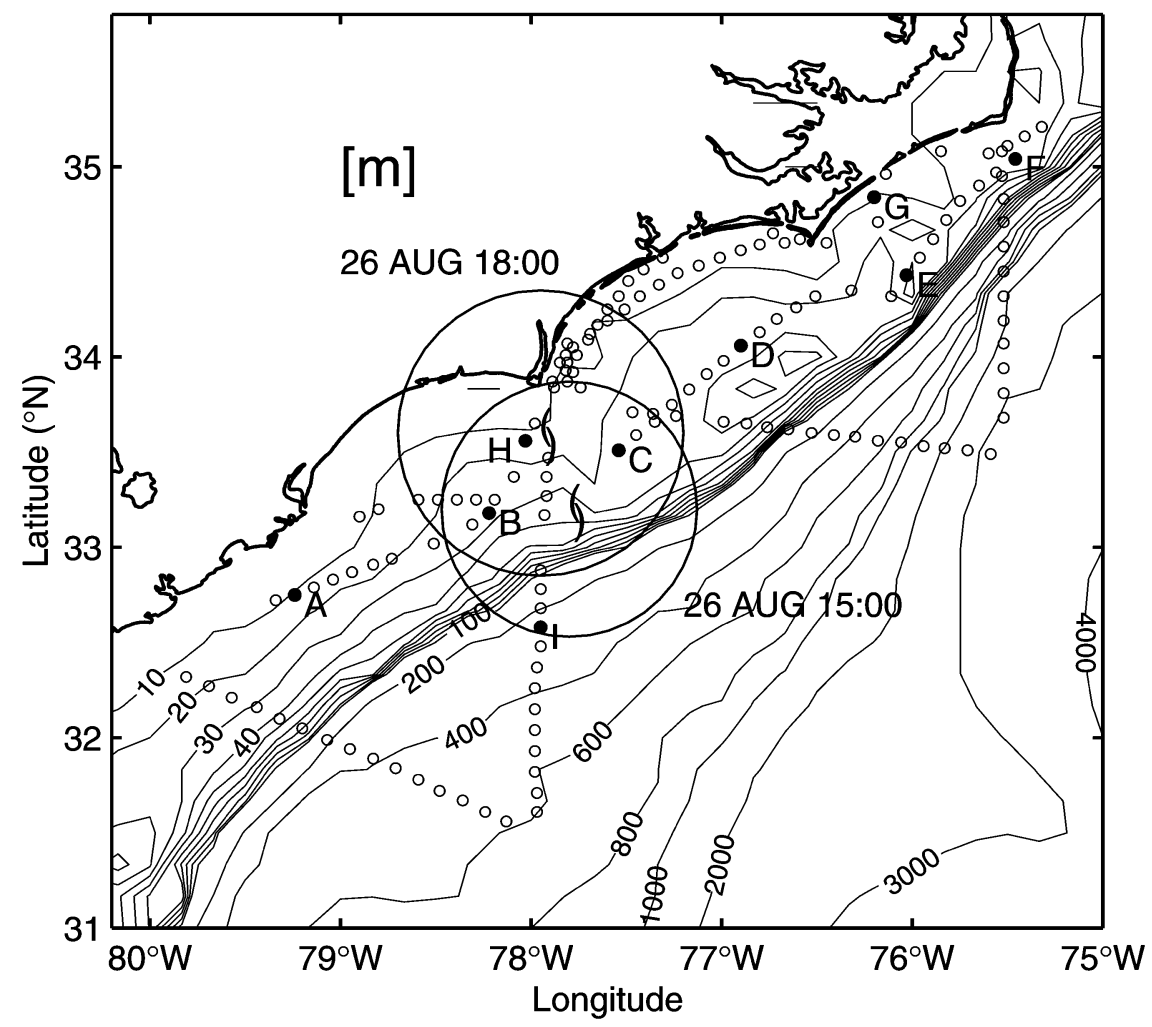


tours), dominant wave direction (arrows), and dominant wavelength (proportional to the arrow length) on 24, 25, 26, and 27 August simulated by the present model The significant wave height reaches $14 \mathrm{~m}$ in the open ocean (Fig. 10c) and it is reduced gradually as the hurricane approaches the shore (Fig. 10d). The maximum wave heights appear in the right forward quadrant of a hurricane center and propagate in the same direction as the hurricane. Comparing Fig. 10b and Fig. 10c, the maximum wave height on 26 August is higher than that on 25 August, even though the observed maximum wind speeds during the two days are the same (Table 1).

Figure 11 is swath pictures of wind, significant wave height, and dominant wavelength, which show the maximum values throughout the hurricane passage. The higher/longer waves appear to the right of the hurricane along its track. However, the maximum height of $14 \mathrm{~m}$ appears from 0600 UTC 25 August, even though the maximum winds are almost the same between 0600 UTC 23 August and 1800 UTC 26 August (Table 1). This appears to be due to the increase of hurricane translation speed from 2 to $8 \mathrm{~m} \mathrm{~s}^{-1}$ between 24 and 26 August (Fig. 3). The effect of the hurricane translation speed on the wave fields will be discussed in section $4 \mathrm{e}$ in detail.

\section{b. Cross section of dominant wave fields}

From the data of SRA directional wave spectrum, Wright et al. (2001) determined primary, secondary, or tertiary wave fields. Figure 12 shows their results of the primary (dominant) wave fields relative to the hurricane center along each flight leg that crossed the hurricane in the open ocean and at landfall. In the open ocean, the swell propagating toward the northwest with 280$315-\mathrm{m}$ wavelength and 9-11-m heights is dominant in the right quadrant of the hurricane. The direction of the swell is roughly aligned with that of the translation of Hurricane Bonnie. This seems to be the result of increased fetch and duration of the wave growth process in the direction of the motion of the storm (MacAfee and Bowyer 2000a,b). For the landfall case, the northwest swell is also dominant in the right quadrant of the hurricane, but has smaller wavelength (about $200 \mathrm{~m}$ ) and height (7-9 m) than in the open ocean, probably due to bathymetric influence.

In Fig. 13, we now compare the simulated significant wave heights, dominant wavelength, and dominant wave direction with the SRA observations along each flight leg in Fig. 12. The general spatial distribution in the SRA measurements and the model simulations show excellent agreement. Mean and rms errors between the SRA and the model (Table 2), which are obtained along the sections across the hurricane, show that the model simulates significant wave heights, dominant wavelength, and wave direction quite well in the open ocean with rms errors of $0.5 \mathrm{~m}, 17 \mathrm{~m}$, and $17^{\circ}$, respectively. For the landfall case, however, the simulated dominant wavelength displays noticeable overestimation, $-45-\mathrm{m}$ mean error, probably due to the model's limitations to handle wave shoaling over shallow areas.

\section{c. Spatial variation of directional wave spectra}

In order to evaluate the model's performance, detailed spectral observation data in all quadrants of a hurricane are necessary because a hurricane produces complex and quickly varying wave spectra in space and time. In this section, the model spectra obtained at various positions relative to Hurricane Bonnie are compared with those of the SRA.

The first dataset of the SRA directional wave spectrum under Hurricane Bonnie was acquired in the open water on 24 August 1998, when Bonnie was 400 km east of Abaco Island, Bahamas. The second dataset was obtained in the region between Charleston, South Carolina, and Cape Hatteras, North Carolina, as Hurricane Bonnie was making landfall near Wilmington, North Carolina, on 26 August 1998. Wright et al. (2001) and Walsh et al. (2002) documented 142 spectra obtained from these measurements. In this study, eighteen spectra among those were selected to be compared with the

FIG. 14. Topography of study areas and measurement points in the (a) open water on 24 Aug 1998 and (b) at landfall on 26 Aug 1998. Small circles represent all SRA measurement points. Filled circles represent the selected points to compare SRA directional spectra with model spectra. Large circles are radii of maximum wind speed during observation.

FIG. 15. (left) SRA directional wave spectra and (right) WW3 spectra in the open water on 24 Aug 1998. The dashed circles (outer to inner) correspond to wavelengths of 150,250 , and $350 \mathrm{~m}$. The solid circles indicate wavelengths of 100, 200, and $300 \mathrm{~m}$. Each spectrum contains nine contours, linearly spaced from $10 \%$ to $90 \%$ of the peak spectral density. The significant wave height and the peak spectral density $\left(\mathrm{m}^{4} \mathrm{rad}^{-2}\right)$ are shown in the upper-right corner of the SRA and the WW3 spectrum. The thick arrows extend in the downwind direction with their length proportional to the (left) HRD surface wind vectors and (right) the model input wind vectors at each point. A wind speed of $30 \mathrm{~m} \mathrm{~s}^{-1}$ corresponds to a length of $0.03 \mathrm{rad} \mathrm{m}^{-1}$. The location north and east of the eye is indicated in the lower-right corner of each WW3 spectrum. The observed and simulated peak wavelengths are in the upper-left corner of the SRA and WW3 spectrum, respectively. Observation time and location are shown in the lower-left and lower-right corner of the SRA spectrum, respectively. Depth of the SRA stations is in the lower-left corner of the WW3 spectrum. 
(a)

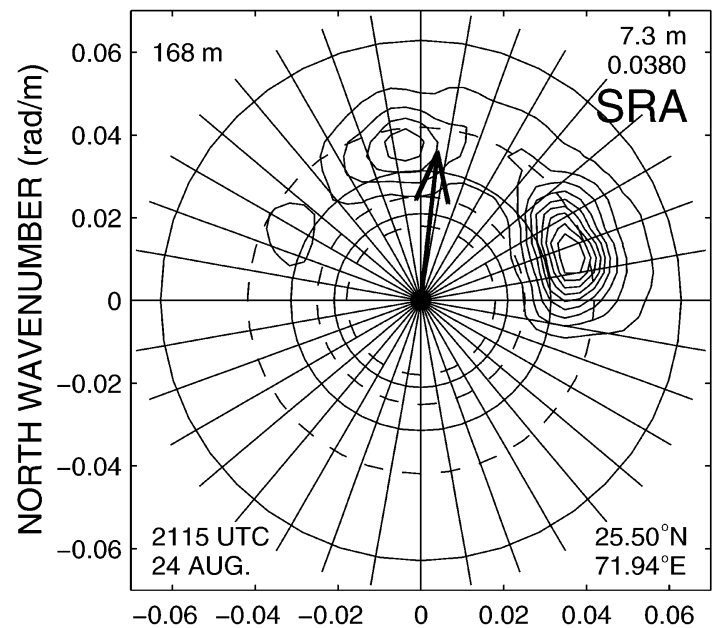

(b)

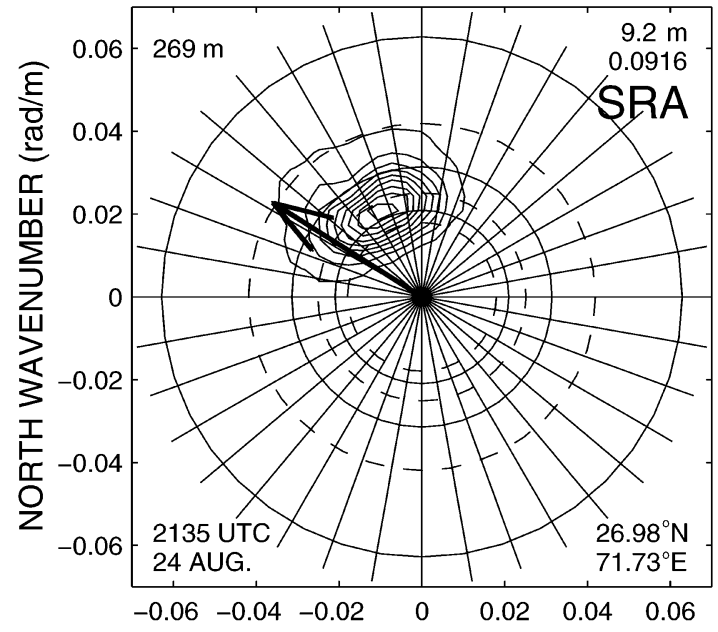

(c)

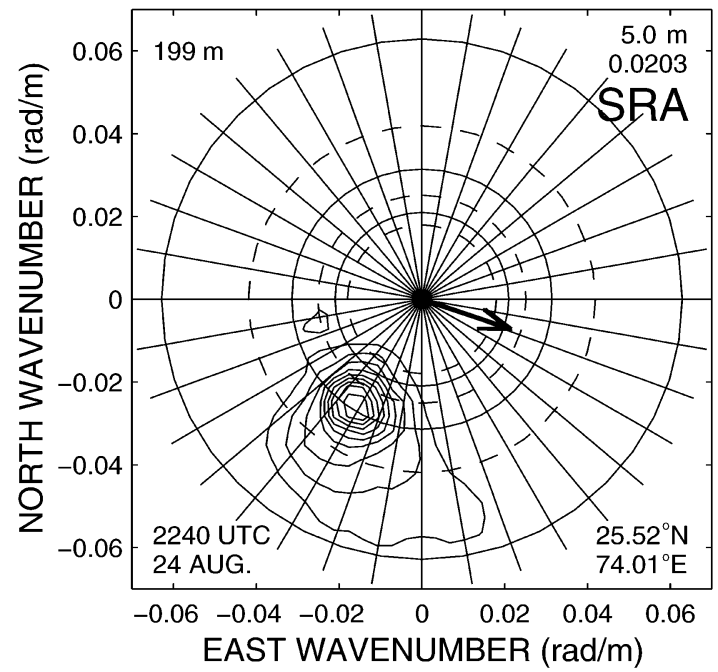

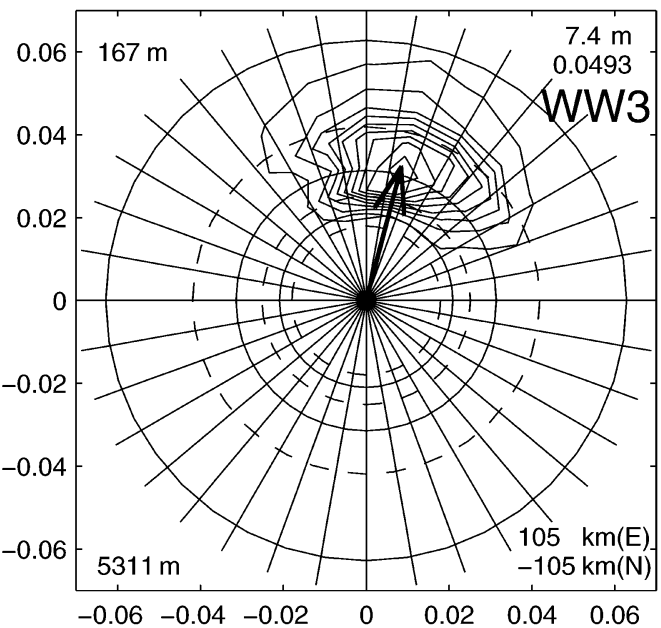
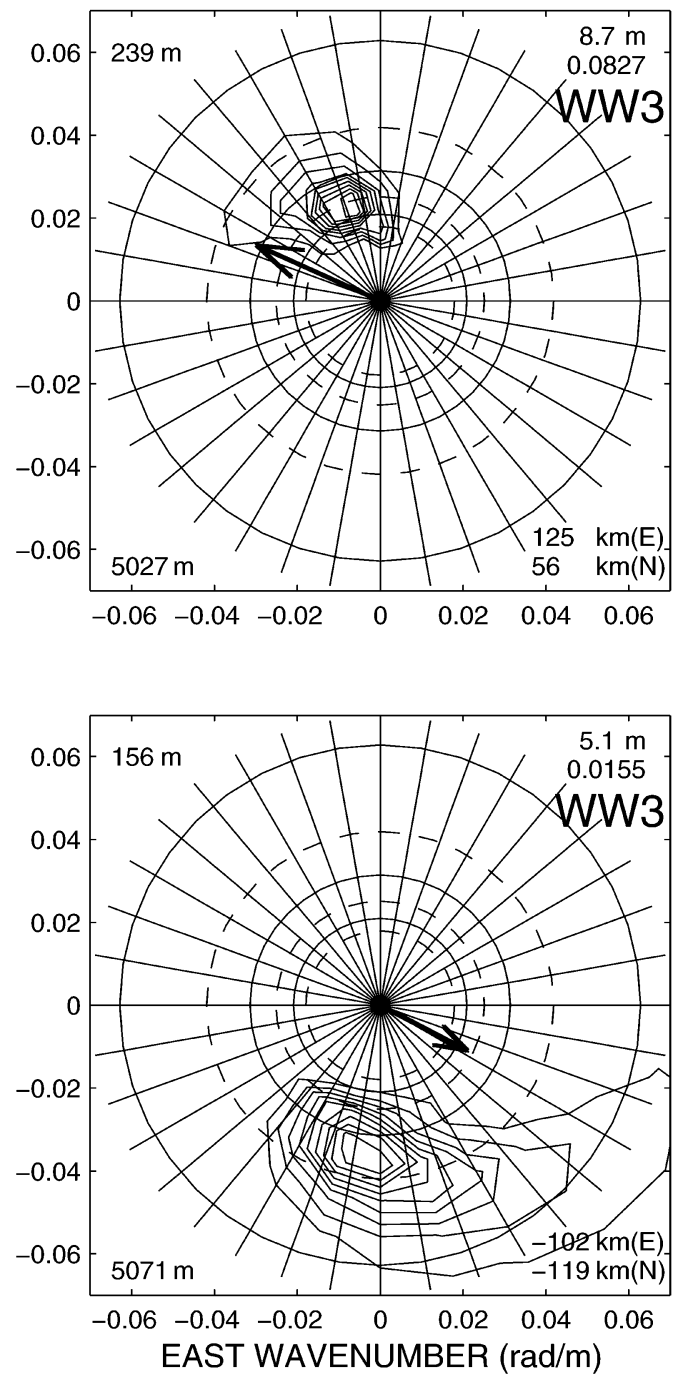
(d)

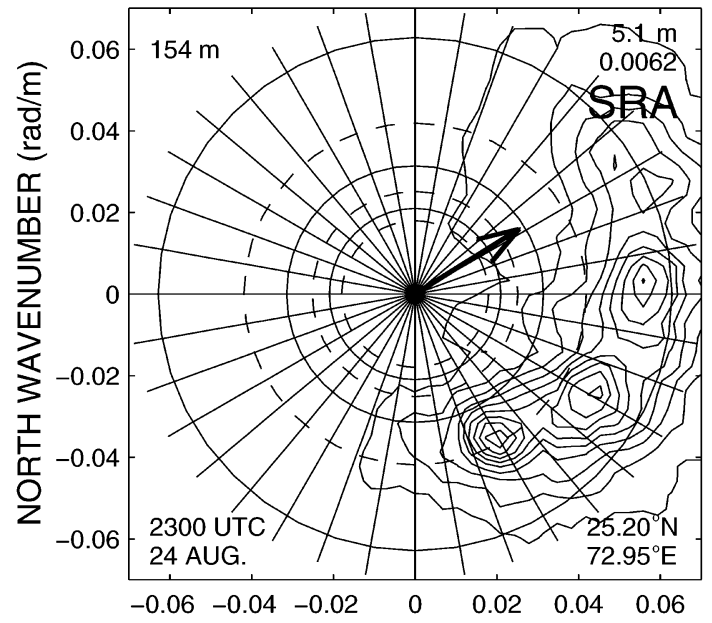

(e)

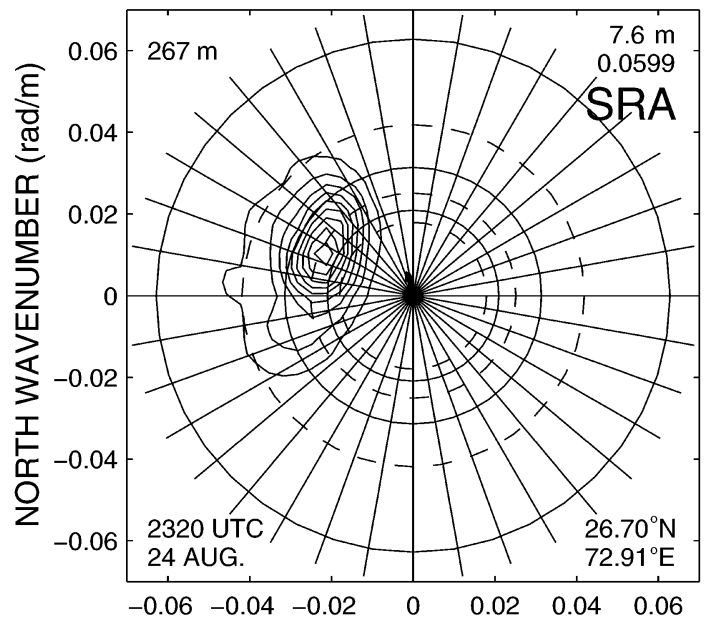

(f)

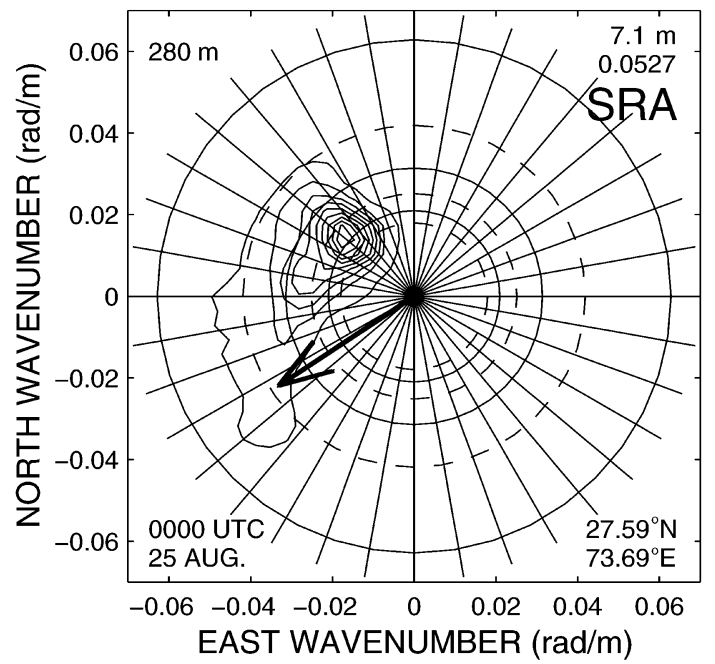

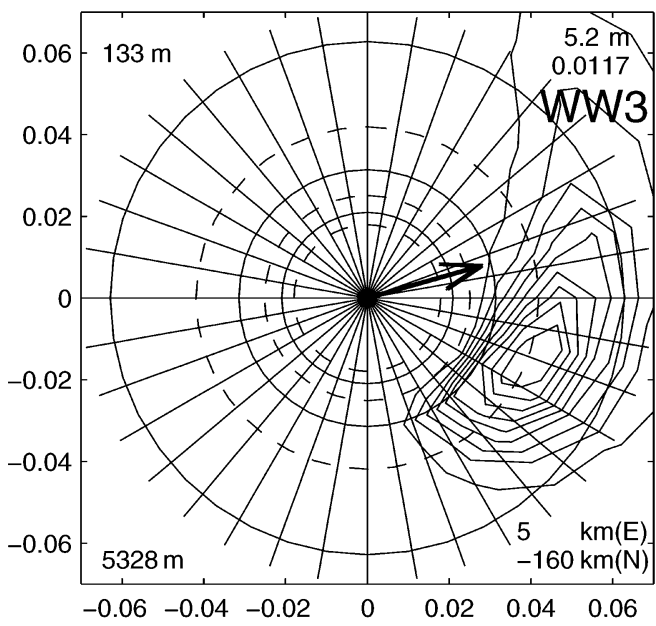
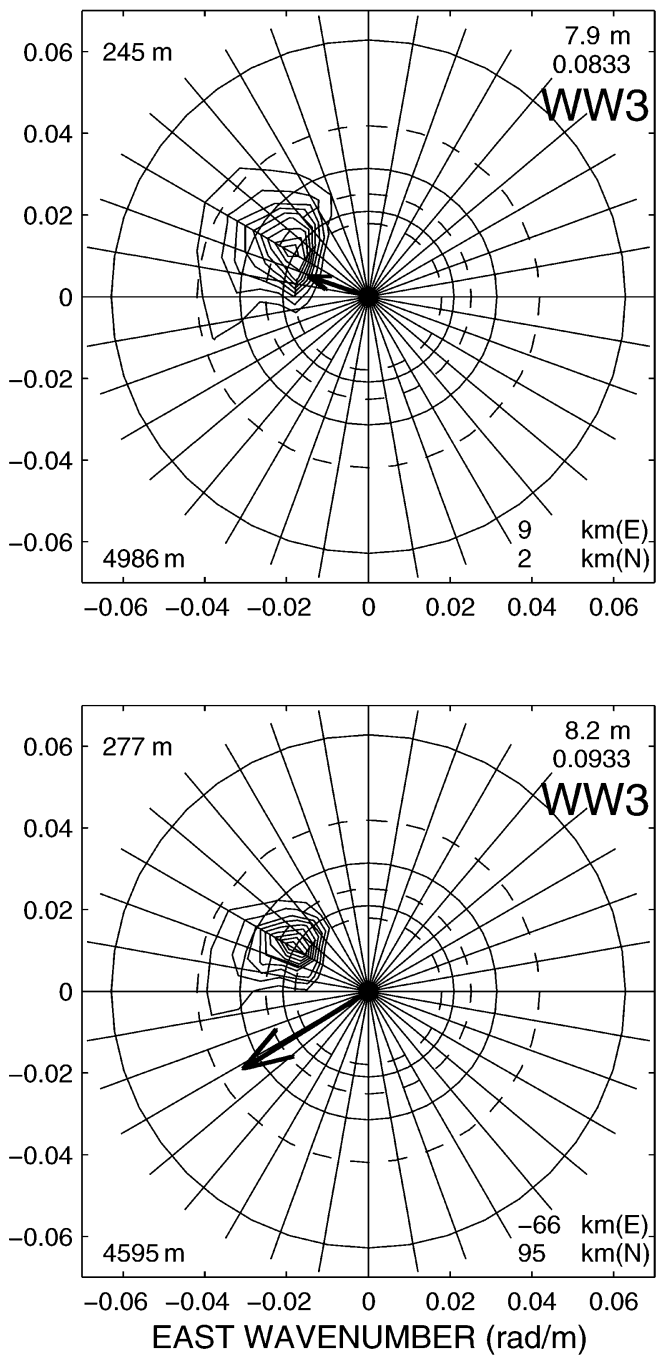

FIG. 15. (Continued) 
(g)

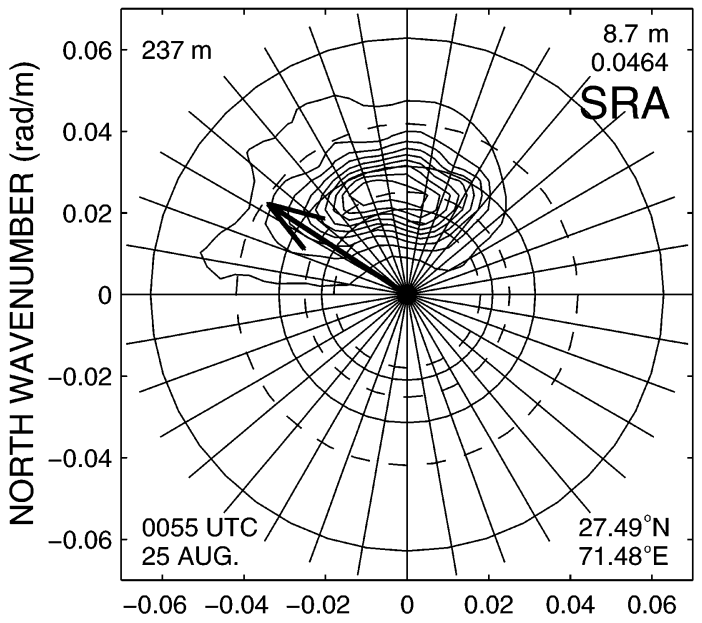

(h)

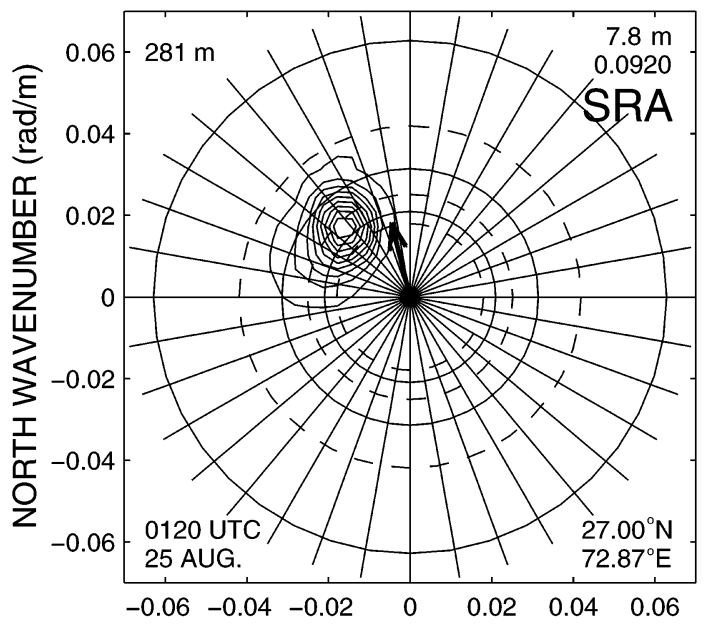

(i)

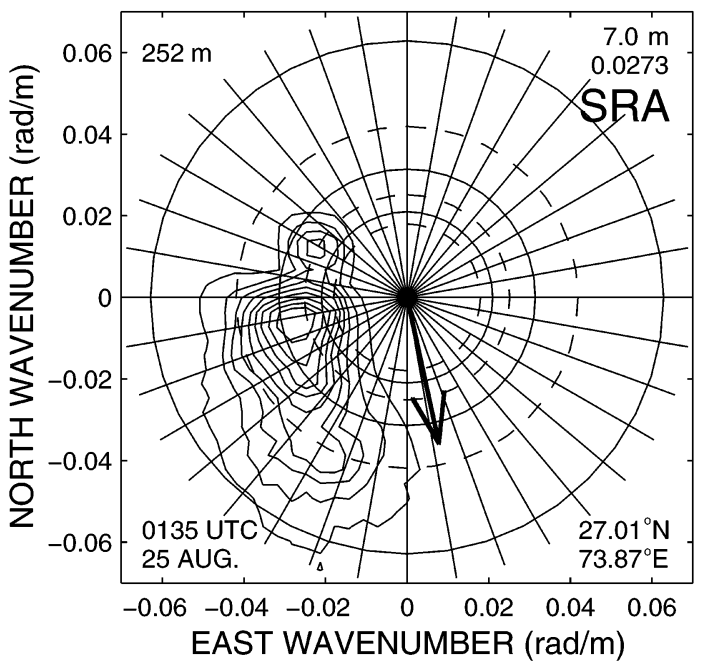

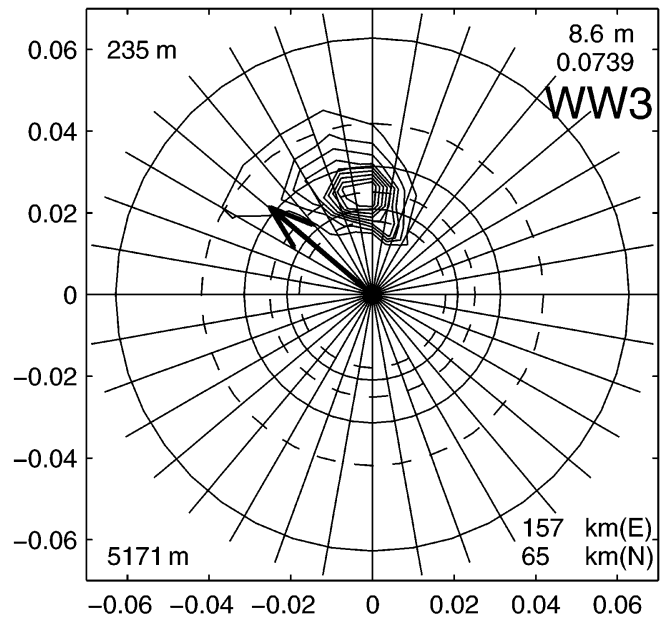
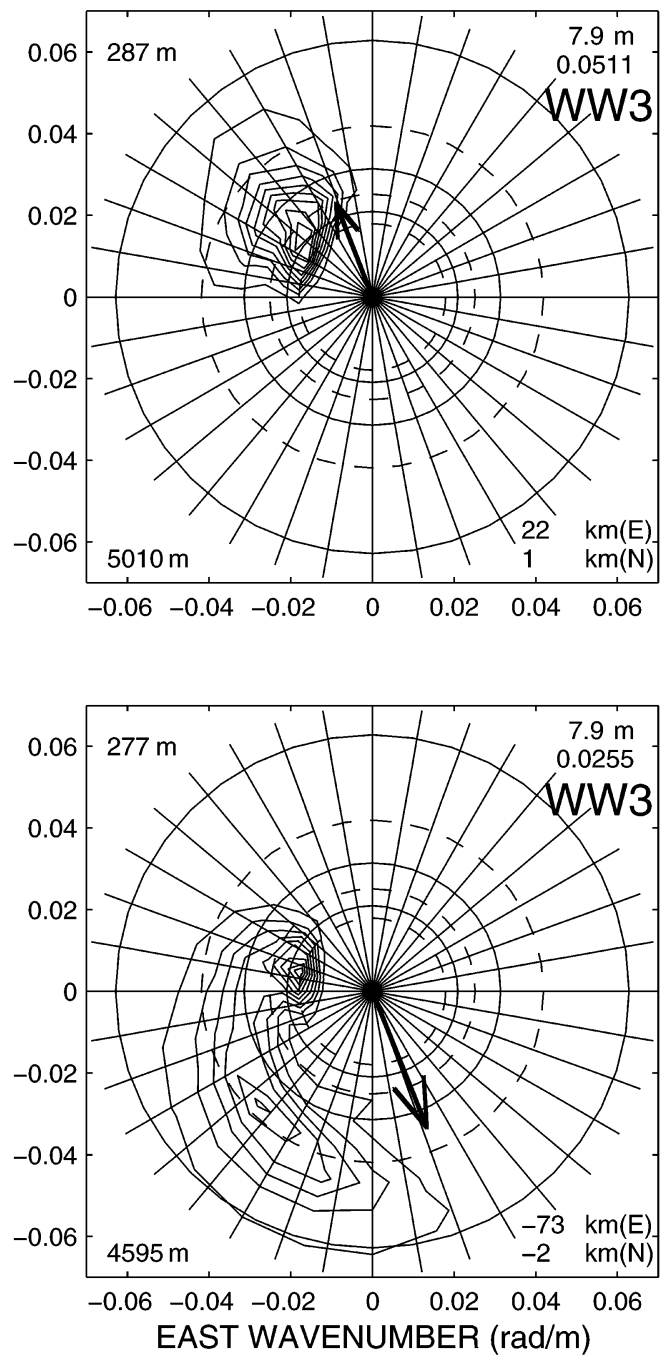

FIG. 15. (Continued) 
(a)

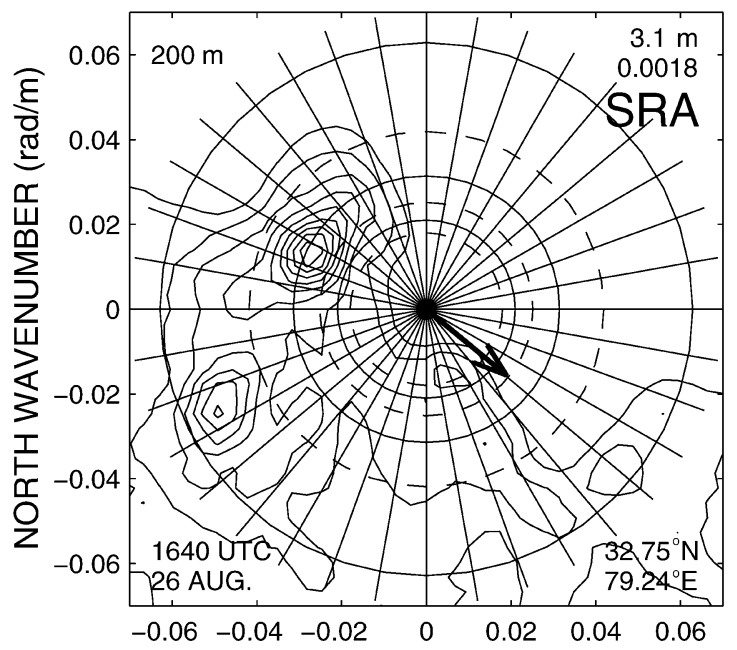

(b)

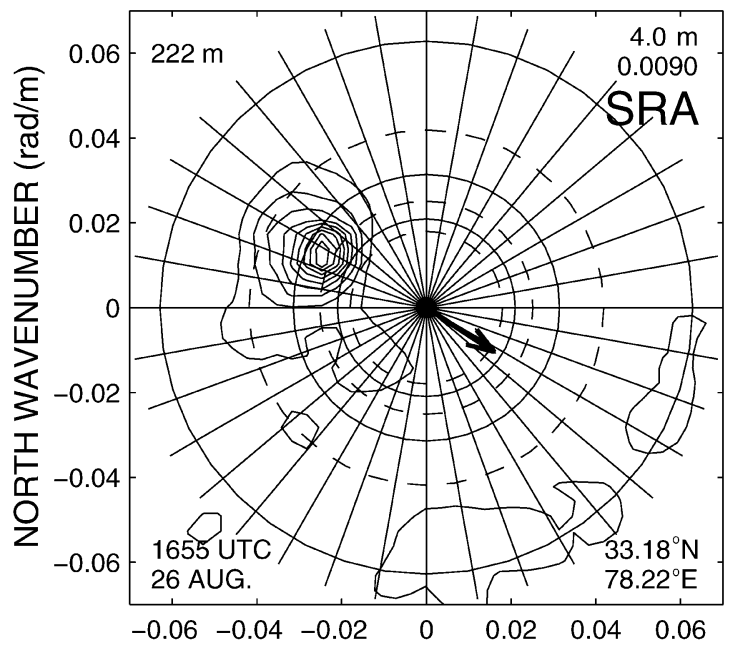

(c)

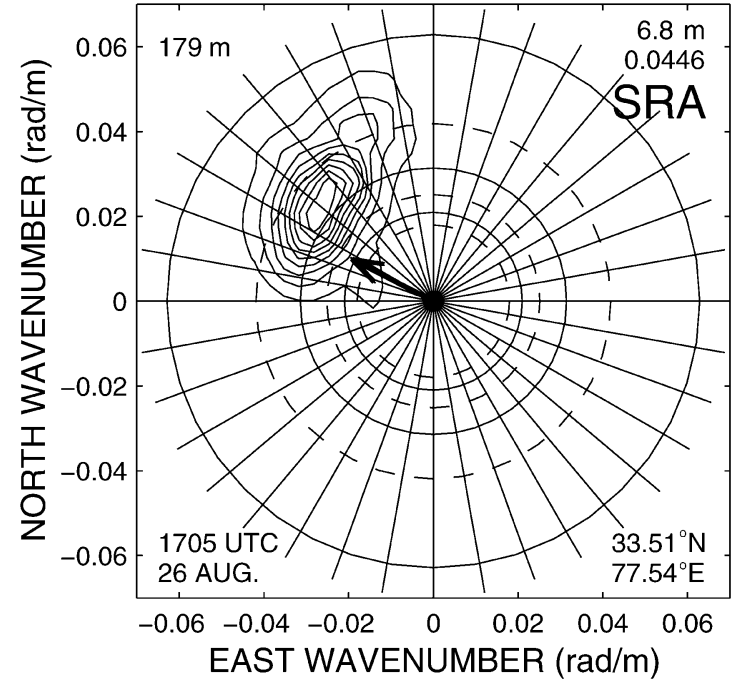

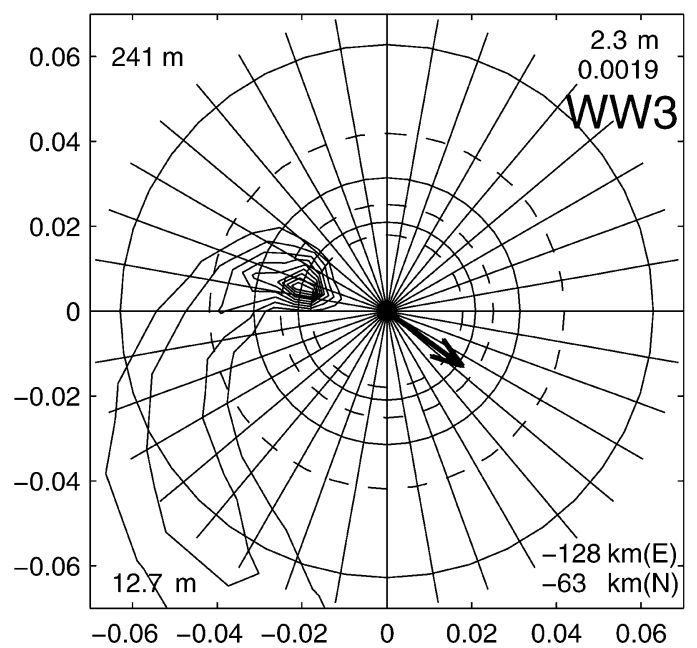
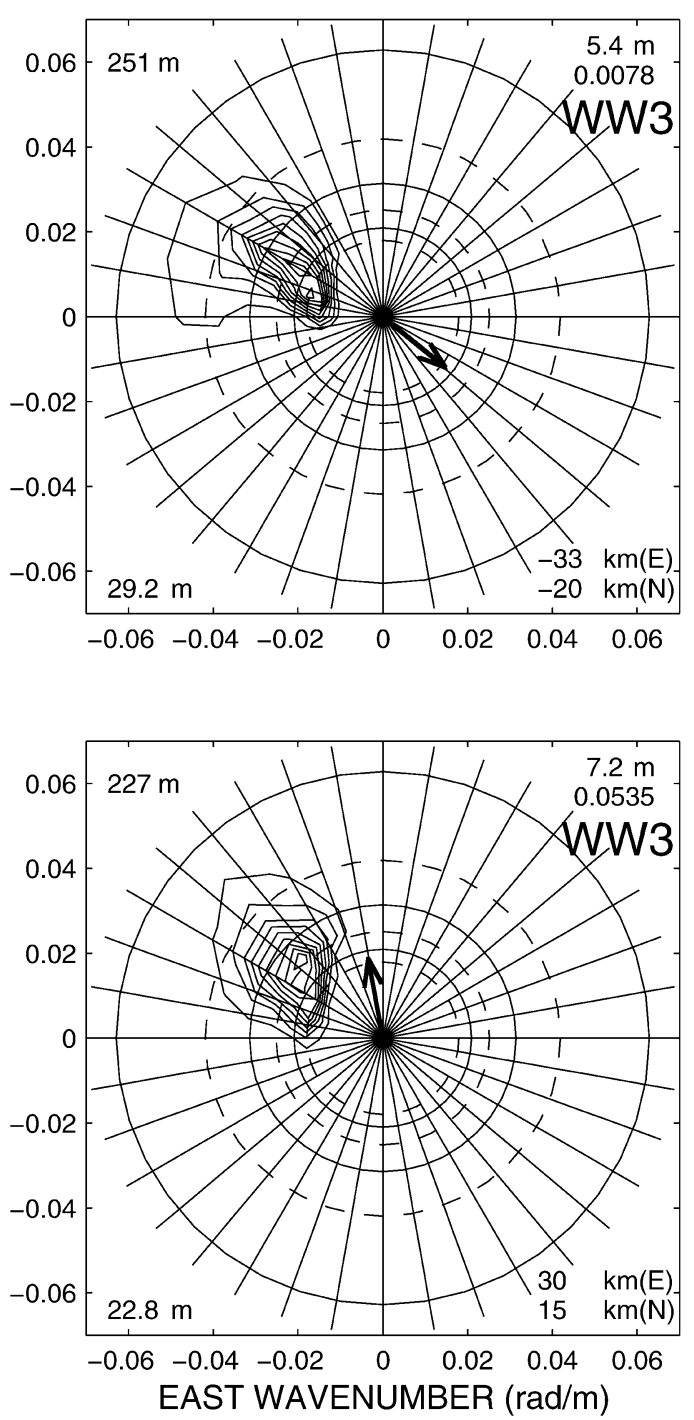

FIG. 16. Same format as in Fig. 15 but with directional wave spectra at landfall of Hurricane Bonnie on 26 Aug 1998. 
(d)

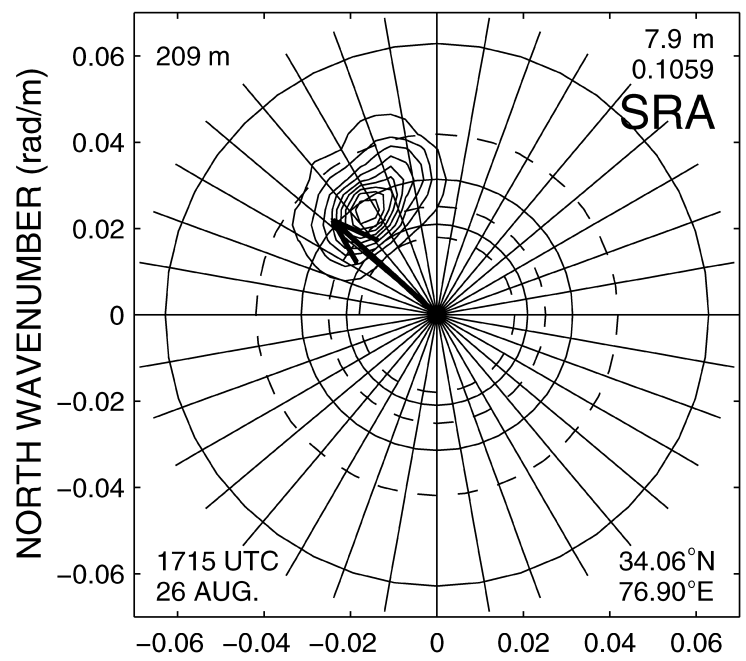

(e)

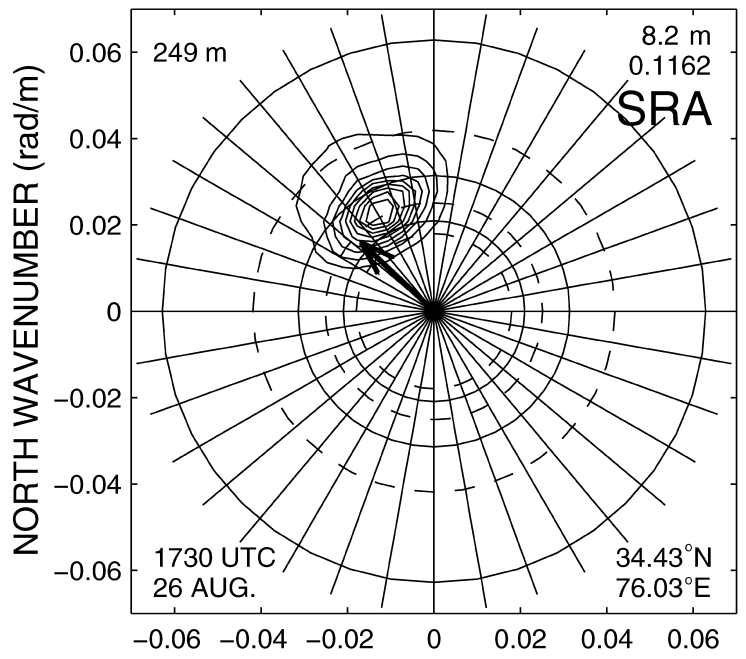

(f)

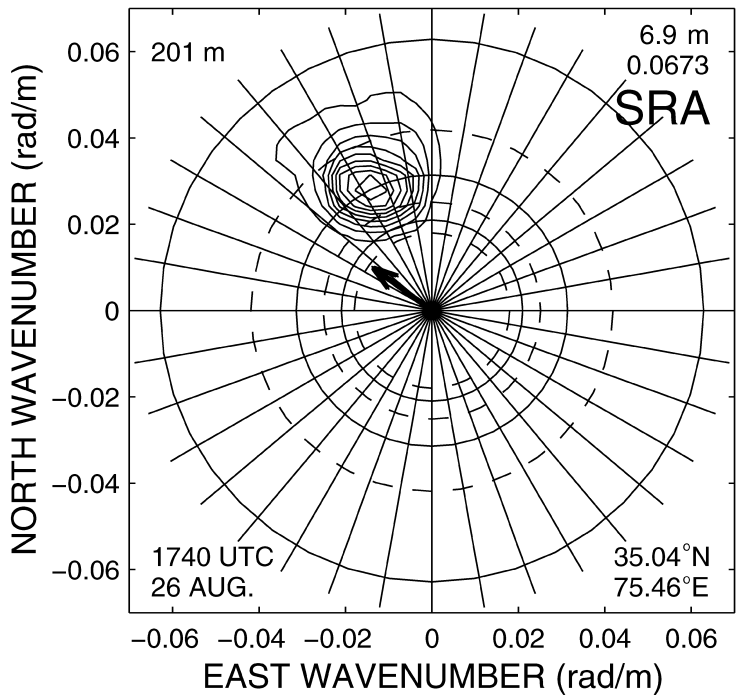

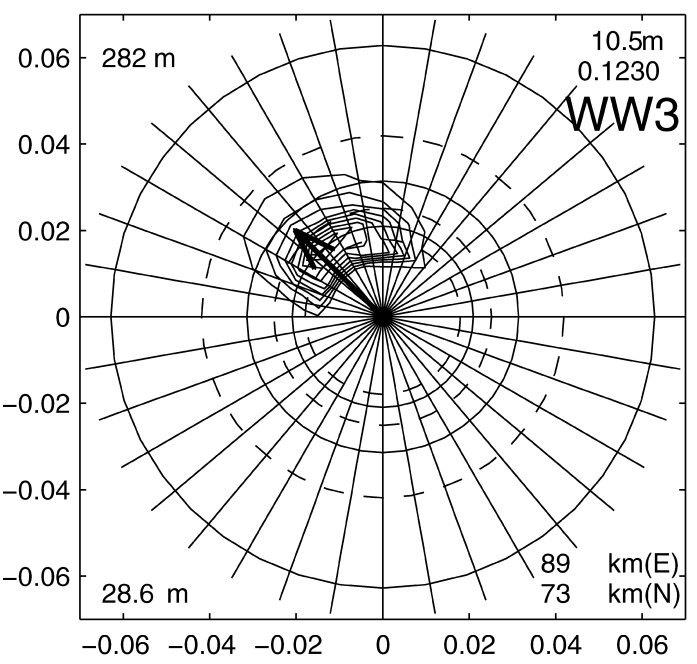
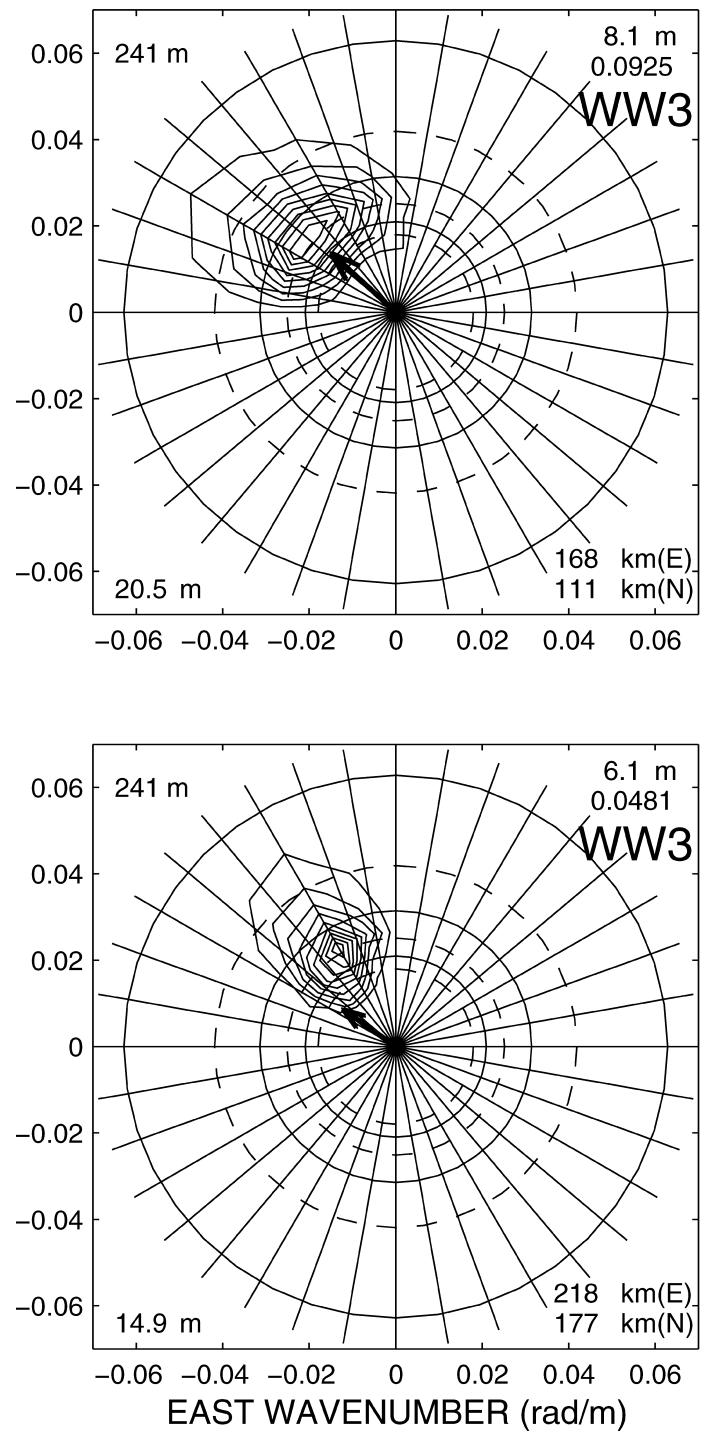

FIG. 16. (Continued) 
(g)

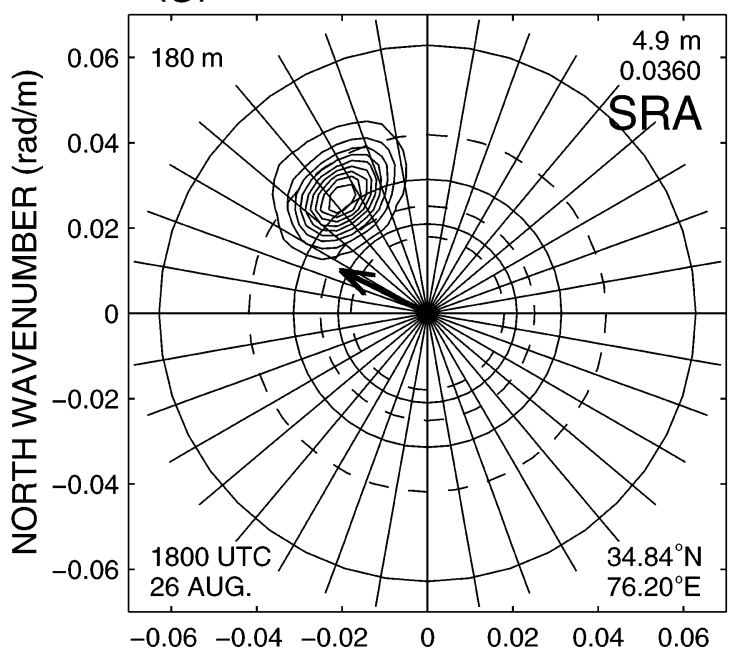

(h)

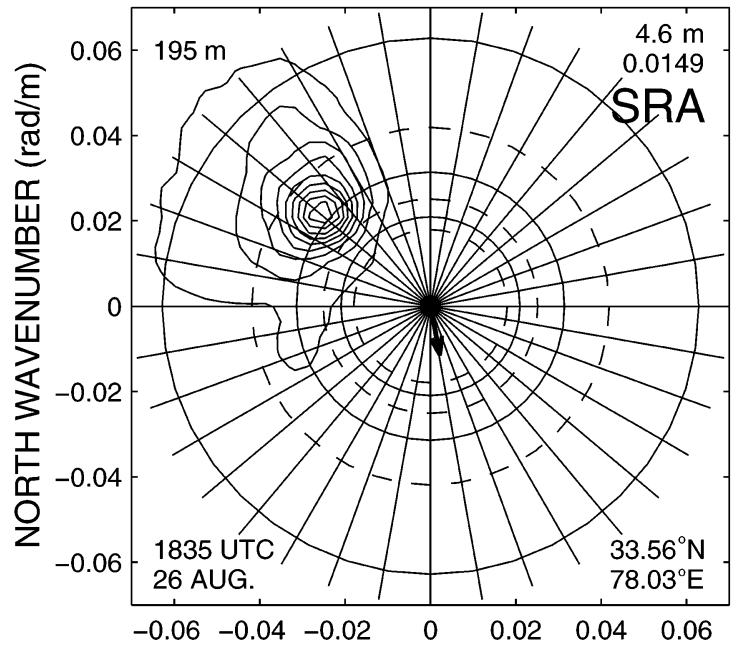

(i)

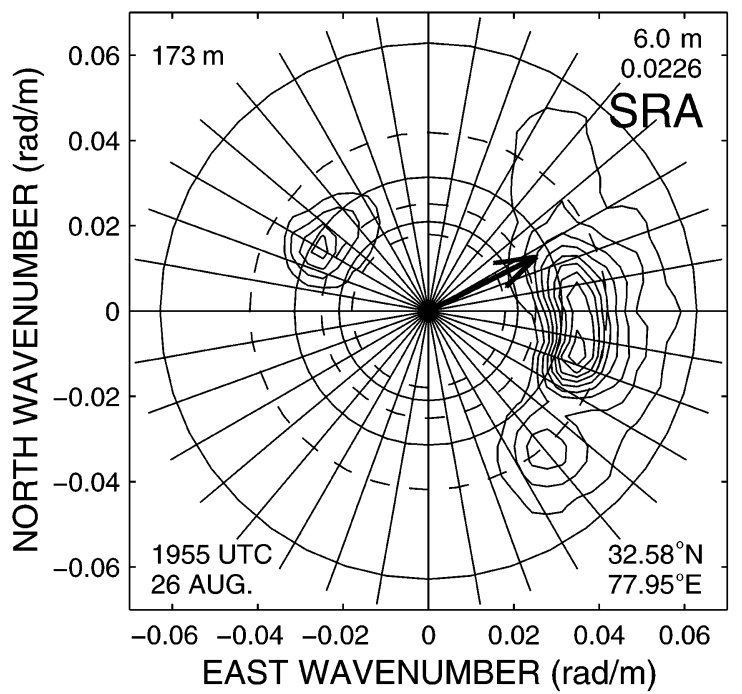

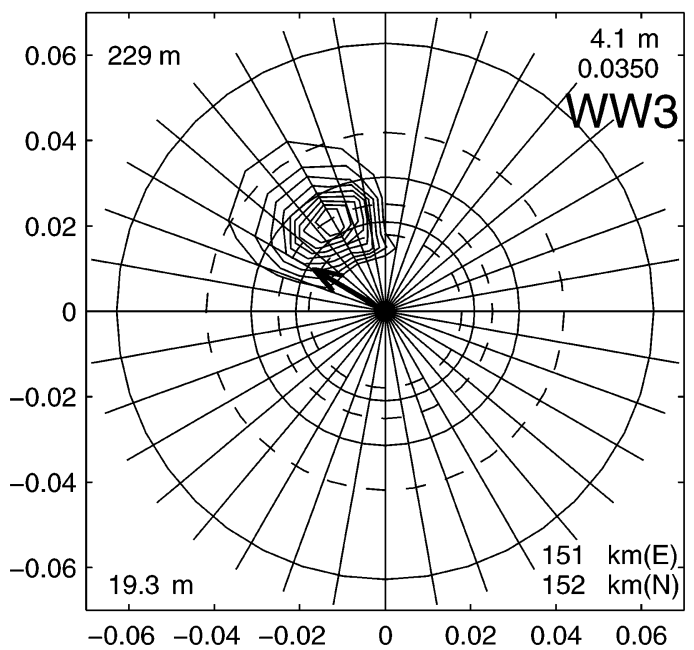
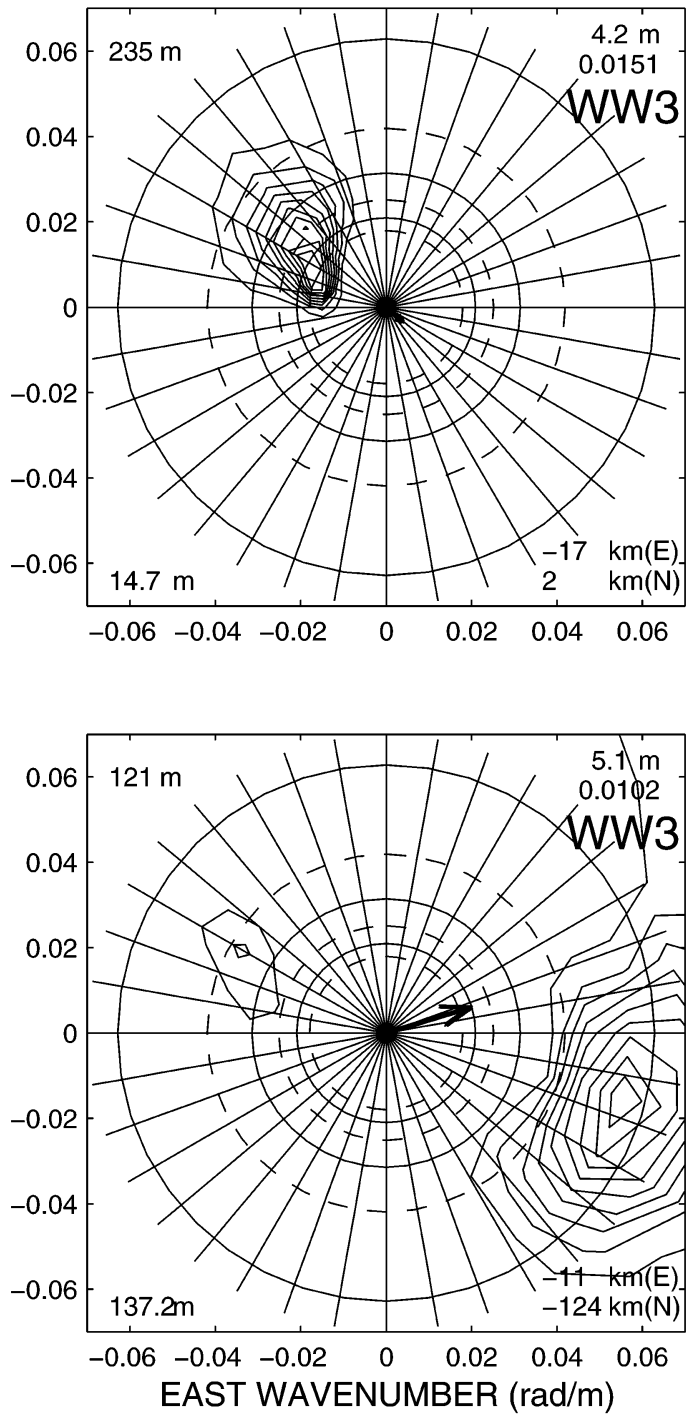

FIG. 16. (Continued) 


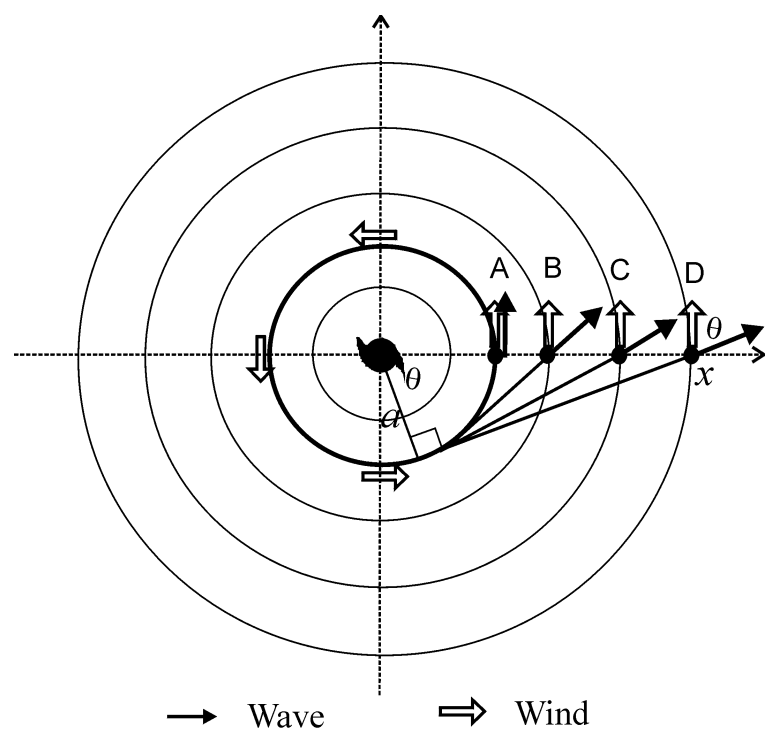

a : Radius of Maximum Wind Speed

FIG. 17. Schematic picture for the misalignment of wind and wave, which depends on distance from RMW.

model spectra. Figure 14 shows the topography of study areas, all SRA measurement points (circles) in the open water (top panel) on 24 August 1998 and at landfall (bottom panel) on 26 August 1998, and the selected points (filled circles) where the SRA directional spectra are compared with the model spectra. Figure 15 shows SRA directional wave spectra and the model spectra in the open water from 2139 UTC 24 August to 0135 UTC 25 August. Figure 16 is in the same format as Fig. 15, but for the landfall case on 26 August 1998.

In the open ocean, direct comparison of the model and SRA directional spectra shows excellent agreement in general, especially in simulating the peak wave direction and frequency. In some cases (Figs. 15a,d), however, the model produces smoother spectra with narrower directional spreading than do the observations when the real spectrum has multiple peaks. A common spectral characteristic observed both in the model and SRA spectra is the misalignment of local wind and waves. At most of the points, except near the hurricane center, dominant waves are consistently found to the right of the wind direction. Explanations for the misalignment will be provided in the following section. Other interesting spectral characteristics are found in the open water: wider directional spread and lower wave heights are to the left of the hurricane (Figs. 15c,d,i) and narrower spread and higher wave heights are to the right of the hurricane (Figs. 15b,g).

For the landfall case, the model and SRA directional spectra are in good agreement, in general, except for peak wavelength. The simulated peak wavelengths displayed noticeable disagreement with the SRA observations at some shallow-depth points (Figs. 16d,g,h), probably due to the model's limitations to handle wave shoaling over shallower depths. The wave spectra to the right of the hurricane show a unimodal swell system propagating in the direction of the hurricane translation (Figs. 16c-g), whereas the spectra in the rear and left

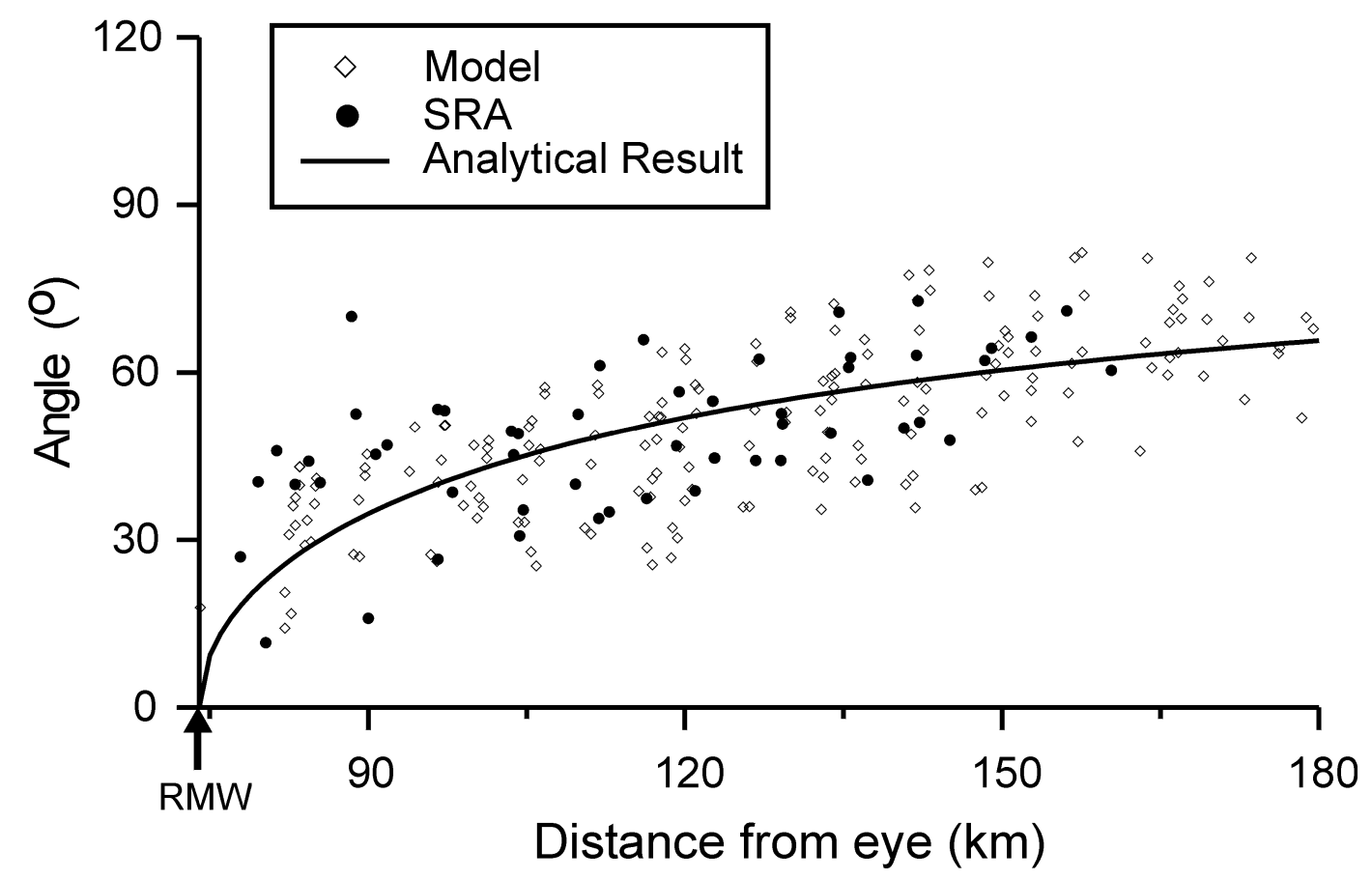

FIG. 18. Comparison among analytical results, SRA, and model for angle difference between local wind and wave in the open ocean. 


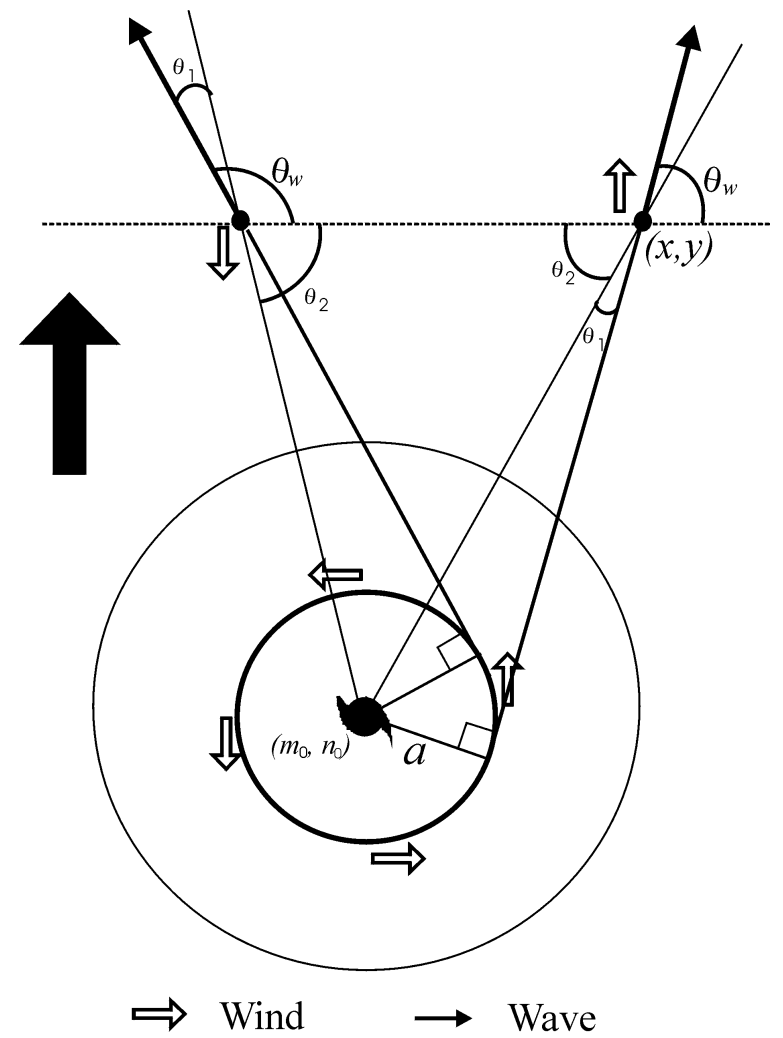

\section{a : Radius of Maximum Wind Speed}

FIG. 19. Schematic picture of swell propagating in the tangential direction from RMW at an earlier position of the storm due to the resonance. Here, $(x, y)$ is observation position, $\left(m_{0}, n_{0}\right)$ is an earlier position of the storm and $\theta_{w}$ is the estimated angle of propagating swell (anticlockwise from the east).

of the hurricane display a more complex structure with both swell and wind wave peaks (Figs. 16a,i). The significant wave heights are larger to the right of the hurricane (Figs. 16d,e) and smaller to the left (Figs. 16a,b).

Spatial variations of the hurricane directional spectra are strongly dependent on the relative position from the hurricane eye (in particular, the distance from the radius of maximum winds) and the hurricane translation speed. These will be discussed in the following two sections.

\section{d. Misalignment of wind and wave under hurricane}

Misalignment of local winds and propagating waves occurs commonly due to the curvature in the hurricane wind fields. Let us consider a symmetric wind field without any hurricane movement and assume that the dominant waves at each point are generated from the wind blowing toward the tangential direction at the radius of maximum winds (RMW). Then the deviation between the winds and waves should increase with the distance from the RMW (Fig. 17). The angle between the waves and winds can be expressed by the following analytical formula:

$$
\theta=\cos ^{-1}(a / x), \quad(x \geq a),
$$

where $a$ is the RMW and $x$ is the distance from storm center.

For the open ocean case, when Hurricane Bonnie was moving very slowly, the angles between local winds and dominant waves estimated from both SRA and model are plotted in Fig. 18 for all points outside of the RMW. Here, the angles are plotted against the distance from the storm center. In the figure, circles and filled circles express the angles obtained from the model and the SRA, respectively. The solid line represents the analytical formula (2) with the RMW, which is set to be $74 \mathrm{~km}$. The figure shows that our simple analytical formula is in reasonable agreement with the result of both observation and model in this case.

For many cases, however, the misalignment may not be well represented by (2) because hurricane winds are typically asymmetric and nonstationary, due to the hurricane's movement. Winds are generally higher (lower) to the right (left) of the hurricane because the forward velocity of the storm adds to the wind velocity around the eye. In addition, the effective fetch and duration of the wave growth process are affected by the motion of the storm. The curvature of the wind field limits the fetch, but waves that propagate in the direction of the storm motion remain under the influence of aligned wind for longer time and distance. Therefore, hurricane translation speed is one of the most important factors determining spatial distribution of directional spectrum.

\section{e. Effect of hurricane translation speed on wave spectra}

Hurricane Bonnie was moving quickly prior to landfall with a maximum translation speed of $8.1 \mathrm{~m} \mathrm{~s}^{-1}$. As the hurricane translation speed increases and becomes comparable to the group speed of dominant waves, waves to the right of the hurricane track are exposed to prolonged forcing from wind; that is, they become "trapped" within the hurricane (resonance effect or dynamic fetch). The trapped waves become dominant swell propagating in the direction of the track and may overwhelm locally generated wind waves at later times.

As indicated above in the open-ocean case, the dominant swell direction is mostly determined by the distance from RMW. This is because Bonnie's translation speed was too small to generate a dominant swell by the resonance effect. The translation speed of 2-5 $\mathrm{m} \mathrm{s}^{-1}$ corresponds to the group velocity of waves of lengths of 10-65 m, so the waves at the peak of the spectrum, with lengths of typically 150-200 m, travel much faster than the storm after they are generated.

For a fast-moving hurricane, by contrast, the dominant swell direction is mostly determined by resonance. The translation speed of $8.1 \mathrm{~m} \mathrm{~s}^{-1}$ of Bonnie prior to landfall matched the group velocity of waves of $168-\mathrm{m}$ length, which is similar to the SRA observed and model 


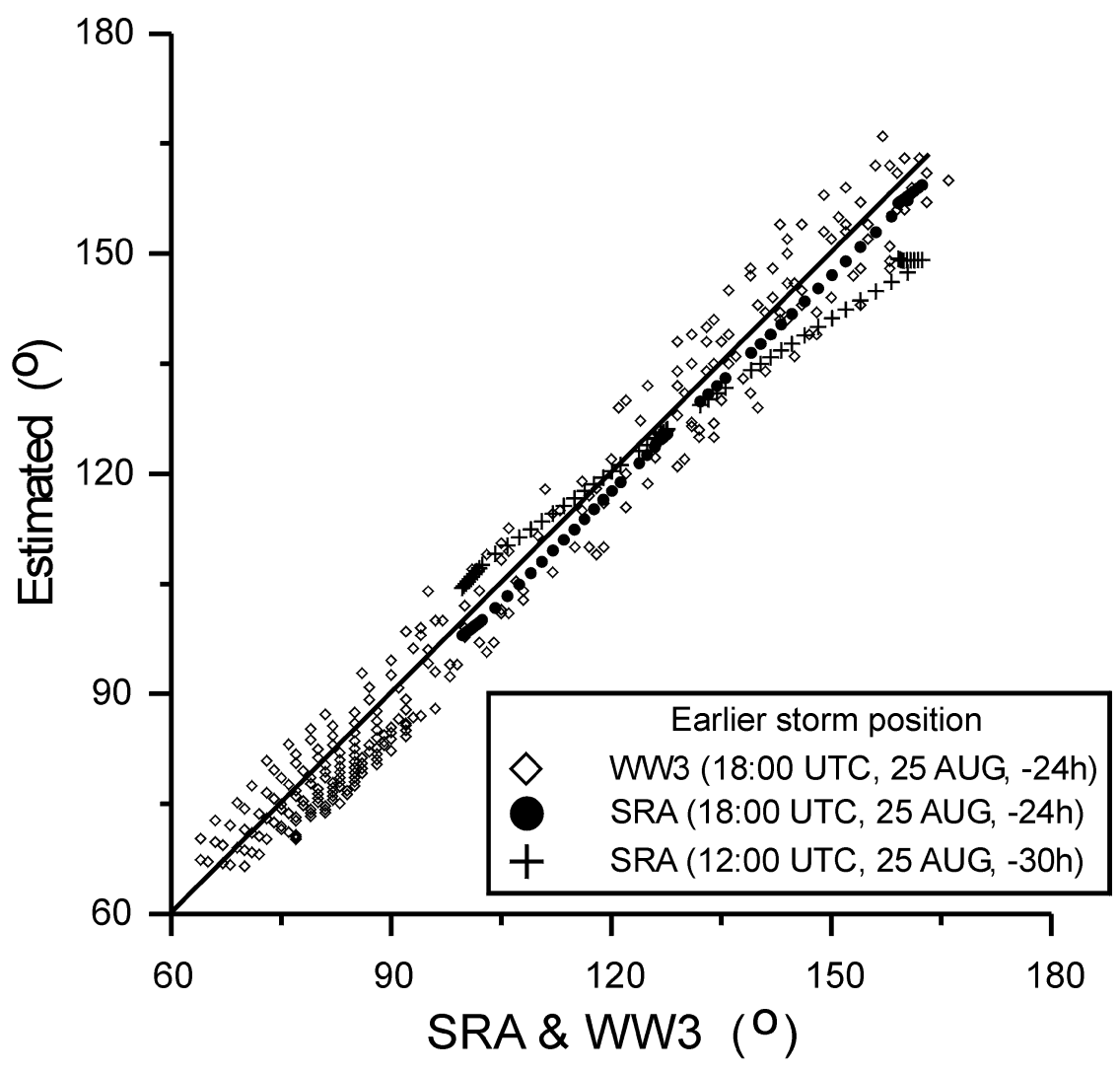

FIG. 20. Comparison among analytical results, SRA, and model for the direction of swell propagating toward the northwest for the landfall case.

simulated dominant wavelength. Therefore, the storm motion increased the effective fetch and duration of waves near the peak of the spectrum. The dominance of swell propagating in the direction of the track is found at most of the stations. In Figs. 16a, 16b, and 16i, the dominant swell is apparent, even to the left and rear of the track, regardless of local wind direction.

Wright et al. (2001) suggested a model for prediction of wave dominance, which is based on the total ability of wind along each $300 \mathrm{~km}$ radial to generate waves propagating toward the observation point. Here, we suggest a simpler model to predict the dominant swell produced by resonance/trapped waves. The model is based on the assumption that the swell is generated from the earlier position of the storm when hurricane translation speed is large and resonance takes place. By this assumption, the propagation direction of the swell at each point is determined by the waves propagating in the tangential direction from RMW at the earlier position of the storm (Fig. 19), provided that the resonance occurred at a large distance from the points. This can be expressed by the following formulas:

$$
\theta_{1}=\sin ^{-1}\left[\frac{a}{\sqrt{\left(x-m_{0}\right)^{2}+\left(y-n_{0}\right)^{2}}}\right]
$$

$$
\begin{aligned}
\theta_{2} & =\tan ^{-1}\left(\left|\frac{y-n_{0}}{x-m_{0}}\right|\right) \\
\theta_{w} & = \begin{cases}\theta_{1}+\pi / 2, & x=m_{0} \\
\theta_{1}+\left(\pi-\theta_{2}\right), & x<m_{0} \\
\theta_{1}+\theta_{2}, & x>m_{0},\end{cases}
\end{aligned}
$$

where $(x, y)$ is the observation position, and $\left(m_{0}, n_{0}\right)$ is the earlier position of the storm. The swell directions estimated by this formula are compared with those from both SRA and model (Fig. 20). Here, only the deep water stations (above $100 \mathrm{~m}$ ) are plotted because the wave direction over shallow water can be affected by refraction due to bathymetry. The earlier positions of the storm are set to be $74.7^{\circ} \mathrm{N}, 28.8^{\circ} \mathrm{E}$ (1200 UTC 25 August) and $75.6^{\circ} \mathrm{N}, 29.8^{\circ} \mathrm{E}$ (1800 UTC 25 August), when the maximum translation speed occurred (Fig. 3). From this picture, it is shown that our simple estimation of swell direction is in excellent agreement with the observations when the earlier storm position is set to $75.6^{\circ} \mathrm{N}, 29.8^{\circ} \mathrm{E}$ (1800 UTC 25 August). The model outputs also follow the analytical rules proposed in this study very well when the earlier storm position is set to $75.6^{\circ} \mathrm{N}, 29.8^{\circ} \mathrm{E}$. 


\section{Summary and conclusions}

Hurricane Bonnie was one of the most powerful hurricanes to directly hit the coast of North Carolina during recent decades, and its translation speed varied from 2 to $8 \mathrm{~m} \mathrm{~s}^{-1}$. In this study, the Hurricane Bonnie directional wave spectra obtained from NASA Scanning Radar Altimeter are compared with ocean wave model results. The wave model, a version of the WAVEWATCH III, uses a high-resolution grid $\left(1 / 12 \times 1 / 12{ }^{\circ}\right)$ to simulate the sea surface spectra of hurricane-generated wind waves. This is the first detailed comparison between model simulations and observations of the spatial distribution of hurricane directional wave spectra in both open ocean and landfall cases.

The modeling results show that, excluding shallow areas near the shore, the model yields an excellent simulation of directional spectrum as well as significant wave height, dominant wavelength, and wave direction under hurricane wind forcing. The present simulation allows more complete analyses of the hurricane-generated wave field than do observations at limited time and space.

From the results of observation and numerical modeling, we have found that the hurricane-generated wave field is mostly determined by two factors: the distance from the hurricane center or the radius of maximum wind and hurricane translation speed. For the case of a hurricane with low translation speed, the dominant wave direction is mainly determined by the distance from the hurricane center. For the case of a fast-moving hurricane, the dominant waves are mostly determined by resonance. When the group velocity of dominant waves is close to the hurricane translation speed, their growth may be significantly enhanced due to the resonance effect, and the swell produced by the resonance dominates wave systems over its propagating areas.

We have suggested simple analytical models for estimating the swell directions for both slow- and fastmoving storms. The swell directions derived from these models demonstrate excellent agreement with those of SRA observation and numerical simulation.

The present study clearly demonstrates that using realistic wind forcing and a high-resolution WAVEWATCH III model may yield successful simulations of surface wave fields in hurricane conditions.

Acknowledgments. For this research Il-Ju Moon, Isaac Ginis, and Tetsu Hara were supported by the National Science Foundation through Grant ATM 0001038.

\section{REFERENCES}

Avila, L. A., cited 1998: Preliminary report: Hurricane Bonnie 1930 August 1998. NOAA National Hurricane Center/Tropical Prediction Center. [Available online at http://www.nhc.noaa.gov/ 1998bonnie.html.]

Barber, N. F., and F. Ursell, 1948: The generation and propagation of ocean waves and swell. Philos. Trans. Roy. Soc. London, 240A, $527-560$.
Bauer, E., S. Hasselmann, K. Hasselmann, and H. C. Graber, 1992: Validation and assimilation of Seaseat altimeter wave heights using the WAM wave model. J. Geophys. Res., 97 (C8), 12 67112682 .

Bender, M. A., and I. Ginis, 2000: Real-case simulations of hurricaneocean interaction using a high-resolution coupled model: Effects on hurricane intensity. Mon. Wea. Rev., 128, 917-946.

Chalikov, D. V., and M. Yu. Belevich, 1993: One-dimensional theory of the wave boundary layer. Bound.-Layer Meteor., 63, 65-96.

Dell'Osso, L., L. Bertotti, and L. Cavaleri, 1992: The Gorbush Storm in the Mediterranean Sea: Atmospheric and wave simulation. Mon. Wea. Rev., 120, 77-90.

Holt, B., A. K. Lie, D. W. Wang, A. Gnanadesikan, and H. S. Chen, 1998: Tracking storm-generated waves in the northeast Pacific Ocean with ERS-1 synthetic aperture radar imagery and buoys. J. Geophys. Res., 103 (C4), 7917-7929.

Komen, G. J., L. Cavaleri, M. Donelan, K. Hasselmann, S. Hasselmann, and P. A. E. M. Janssen, 1994: Dynamics and Modeling of Ocean Waves. Cambridge University Press, $520 \mathrm{pp}$

MacAfee, A. W., and P. J. Bowyer, 2000a: Trapped-fetch waves in a transitioning tropical cyclone (Part I: The need and the theory). Preprints, 24th Conf. on Hurricanes and Tropical Meteorology, Fort Lauderdale, FL, Amer. Meteor. Soc., 292-293.

$\ldots$, and $\longrightarrow, 2000 \mathrm{~b}$ : Trapped-fetch waves in a transitioning tropical cyclone (Part II: Analytical and predictive model). 24th Conf. on Hurricanes and Tropical Meteorology, Fort Lauderdale, FL, Amer. Meteor. Soc., 165-166.

Monaldo, F. M., and R. C. Beal, 1998: Comparison of SIR-C SAR wavenumber spectra with WAM model predictions. J. Geophys. Res., 103 (C9), 18 815-18 825.

Powell, M. D., S. H. Houston, and T. Reinhold, 1996: Hurricane Andrew's landfall in south Florida. Part I: Standardizing measurements for documentation of surface wind fields. Wea. Forecasting, 11, 304-328.

Prasadkumar, B., R. Kalra, S. K. Dube, P. C. Sinha, A. D. Rao, R. Kumar, and A. Sarkar, 2000: Extreme wave conditions over the Bay of Bengal during severe cyclone-Simulation experiment with two spectral wave models. Mar. Geod., 23, 91-102.

Shearman, R. J., and A. A. Zelenko, 1989: Wind measurements reduction to a standard level. Marine Meteorology and Related Oceanography Activities Rep. 22, WMO/TD 311, 30 pp.

Tolman, H. L., 1989: The numerical model WAVEWATCH: A third generation model for the hindcasting of wind waves on tides in shelf seas. Communications on Hydraulic and Geotechnical Engineering Rep. 89-2, Delft University of Technology, 72 pp.

__ 1991: A third-generation model for wind waves on slowly varying, unsteady, and inhomogeneous depths and currents. $J$. Phys. Oceanogr., 21, 782-797.

- 1992: Effects of numerics on the physics in a third-generation wind-wave model. J. Phys. Oceanogr., 22, 1095-1111.

_ 1998: Validation of a new global wave forecast system at NCEP. Ocean Wave Measurements and Analysis, B. L. Edge and J. M. Helmsley, Eds., ASCE, 777-786.

1999: User manual and system documentation of WAVEWATCH-III version 1.18. Tech. Note 166, Ocean Modeling Branch, NCEP, National Weather Service, NOAA, U.S. Department of Commerce, $110 \mathrm{pp}$. [Available online at http:// polar.wwb.noaa.gov/waves/wavewatch.]

_- 2002: Validation of WAVEWATCH III version 1.15 for a global domain. NOAA/NWS/NCEP/OMB Tech. Note 213, 33 pp. [Available online at http://polar.ncep.noaa.gov/waves/references.html.]

_ , and D. Chalikov, 1996: Source terms in a third-generation wind wave model. J. Phys. Oceanogr., 26, 2497-2518.

- B. Balasubramaniyan, L. D. Burroughs, D. Chalikov, Y. Y. Chao, H. S. Chen, and V. M. Gerald, 2002: Development and implementation of wind-generated ocean surface wave models at NCEP. Wea. Forecasting, 17, 311-333.

Walsh, E. J., D. W. Hancock, D. E. Hines, R. N. Swift, and J. F. Scott, 1985: Directional wave spectra measured with the surface contour radar. J. Phys. Oceanogr., 15, 566-592. 
, and Coauthors, 2002: Hurricane directional wave spectrum spatial variation at landfall. J. Phys. Oceanogr., 32, 1667-1684.

WAMDI group, 1988: The WAM model-A third generation ocean wave prediction model. J. Phys. Oceanogr., 18, 1775-1810.

Wingeart, K. M., W. C. O'Reilly, T. H. C. Herbers, P. A. Wittmann, R. E. Jenssen, and H. L. Tolman, 2001: Validation of operational global wave prediction models with spectral buoy data. Ocean
Wave Measurement and Analysis, B. L. Edge and J. M. Hemsley, Eds., ASCE, 590-599.

Wright, C. W., and Coauthors, 2001: Hurricane directional wave spectrum spatial variation in the open ocean. J. Phys. Oceanogr., 31, $2472-2488$.

Wyatt, L. R., 1995: The effect of fetch on the directional spectrum of Celtic Sea storm waves. J. Phys. Oceanogr., 25, 1550-1559. 